\title{
Evaluation of cytotoxicity profile and intracellular localisation of doxorubicin-loaded chitosan nanoparticles
}

\author{
Gabriele Dadalt Souto \\ Technological University Dublin \\ Zeineb Farhane \\ Technological University Dublin \\ Esen Efeoglu \\ Technological University Dublin
}

See next page for additional authors

Follow this and additional works at: https://arrow.tudublin.ie/biophonart

Part of the Biochemistry, Biophysics, and Structural Biology Commons, Medicinal Chemistry and Pharmaceutics Commons, and the Physics Commons

\section{Recommended Citation}

"Evaluation of cytotoxicity profile and intracellular localisation of doxorubicin-loaded chitosan nanoparticles", Gabriele Dadalt Souto, Zeineb Farhane,Alan Casey, Esen Efeoglu, Jennifer McIntyre, Hugh James Byrne, Analytical and Bioanalytical Chemistry, 408, 5443-5455 (2016)

This Article is brought to you for free and open access by the DIT Biophotonics and Imaging at ARROW@TU Dublin. It has been accepted for inclusion in Articles by an authorized administrator of ARROW@TU Dublin. For more information, please contact arrow.admin@tudublin.ie, aisling.coyne@tudublin.ie,gerard.connolly@tudublin.ie. Funder: GDS was funded by the Brazilian National Council for Scientific and Technological Development (CNPq), through the Science without BordersProgram grant \#236817/2013-2. ZF, AC, EE, JMcl and HJB are supported by Science Foundation Ireland Principle Investigator Award 11/Pl/1108.

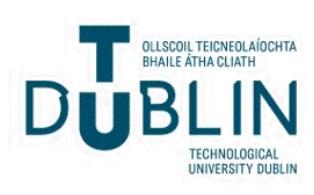




\section{Authors}

Gabriele Dadalt Souto, Zeineb Farhane, Esen Efeoglu, Alan Casey, Jennifer Mclntyre, and Hugh Byrne 
1 Evaluation of cytotoxicity profile and intracellular localisation of doxorubicin-loaded

2 chitosan nanoparticles

3

4 Gabriele Dadalt Souto ${ }^{1, *}$

5 Zeineb Farhane $e^{1,2}$

$6 \quad$ Alan Casey ${ }^{1}$

$7 \quad$ Esen Efeoglu ${ }^{1,2}$

8 Jennifer McIntyre ${ }^{1}$

$9 \quad$ Hugh James Byrne ${ }^{1}$

10

$11{ }^{1}$ FOCAS Research Institute, Dublin Institute of Technology, Kevin Street, Dublin 8, Ireland

$12{ }^{2}$ School of Physics, Dublin Institute of Technology, Kevin Street, Dublin 8, Ireland 13

14 *Corresponding author

15 Present address: Faculdade de Farmácia, Universidade do Rio Grande do Sul, Porto Alegre 16 RS, 90610-000, Brazil

17 Phone number: +555133085215

18 E-mail: gabrieledadalt@gmail.com

20 Funding

21 GDS was funded by the Brazilian National Council for Scientific and Technological

22 Development (CNPq), through the Science without BordersProgram grant \#236817/2013-2.

$23 \mathrm{ZF}, \mathrm{AC}, \mathrm{EE}, \mathrm{JMcI}$ and HJB are supported by Science Foundation Ireland Principle

24 Investigator Award 11/PI/1108. 


\section{Abstract}

27

28 In the emerging field of nanomedicine, targeted delivery of nanoparticle encapsulated active pharmaceutical ingredients (API) is seen as a potential significant development, promising improved pharmacokinetics and reduced side effects. In this context, understanding the cellular uptake of the nanoparticles and subsequent subcellular distribution of the API is of critical importance. Doxorubicin (DOX) was encapsulated within chitosan nanoparticles to investigate its intracellular delivery in A549 cells in vitro. Unloaded (CS-TPP) and

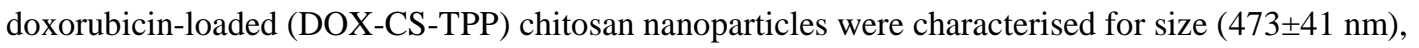
polydispersity index $(0.3 \pm 0.2)$, zeta potential $(34 \pm 4 \mathrm{mV})$, drug content $(76 \pm 7 \mu \mathrm{M})$ and encapsulation efficiency $(95 \pm 1 \%)$. The cytotoxic response to DOX-CS-TPP was substantially stronger than to CS-TPP, although weaker than that of the equivalent free DOX. Fluorescence microscopy showed a dissimilar pattern of distribution of DOX within the cell, being predominantly localised in the nucleus for free form and in cytoplasm for DOX-CSTPP. Confocal microscopy demonstrated endosomal localisation of DOX-CS-TPP. Numerical simulations, based on a rate equation model to describe the uptake and distribution of the free DOX, nanoparticles and DOX loaded nanoparticles within the cells, and the subsequent dose and time dependent cytotoxic responses, were used to further elucidate the API distribution processes. The study demonstrates that encapsulation of the API in nanoparticles results in a delayed release of the drug to the cell, resulting in a delayed cellular response. This work further demonstrates the potential of mathematical modelling in combination with intracellular imaging techniques to visualise and further understand the intracellular mechanisms of action of external agents, both APIs and nanoparticles in cells.

Keywords: nanomedicine, doxorubicin, chitosan nanoparticles, in vitro cytotoxicity, numerical simulations. 


\section{Introduction}

59 Encapsulation of active pharmaceutical ingredients (API) in nanoparticle delivery vehicles potentially enables: targeting of specific tissues or cells, release of the API in a controlled manner, and/or reduction of the necessary dose, thereby reducing potential side effects (e.g. toxicity) of the treatment [1,2]. The greater specific surface area of nanoparticles, due to reduced size, enables greater biological activity and reactivity, when compared to larger particles [3], and therefore the biocompatibility of the nanocarriers themselves must be assured and adequate toxicity studies must be performed, in vitro and in vivo. Furthermore, it is important to study the nanoparticle uptake and trafficking mechanisms as well as the drug release at cellular and subcellular level. In this context, the in vitro study using model loaded nanoparticle drug systems, and kinetic modelling of response can add much to the understanding of the drug delivery processes.

69 Nevertheless, problems related to resistance development [5], acute cardiotoxicity [6], low penetration and limited distribution in solid tumours [7], have led to investigations of alternative forms of administration. The majority of research has involved the association of doxorubicin to liposomes, exploring the interactions between lipid and drug charges [8]. However, indications of dermal and renal toxicity have been observed $[9,10]$. An alternative approach is to encapsulate doxorubicin within a positively charged nanocarrier, which would favour cellular adhesion and uptake, as cell membranes are negatively charged [11]. recognised as safe, it has demonstrated biocompatible, non immunogenic, non toxic and biodegradable properties, and is thus a good candidate for pharmaceutical and biomedical applications $[12,13]$. In addition, considering intravenous administration, positively charged particles would interact with different blood components, which can favour different patterns of organ biodistribution and/or accumulation [14]. Chitosan nanoparticles can be formulated through several techniques, such as coacervation, co-precipitation, solvent evaporation, ionotropic gelation, and microemulsion, among others $[11,15,16]$. It should be noted that, although some regulatory definitions of nanoparticles restrict the term to a "particle with one or more dimensions of the order of $100 \mathrm{~nm}$ or less" [17], in other fields, such as Nanomedicine, the term is used to cover a broader size range and, for example, the International Standards Organisation Technical Committee on Nanotechnologies describes the "understanding and control of matter and processes at the nanoscale, typically, but not exclusively, 


\section{Materials and Methods}

\section{1}

\section{Materials}

\section{3}

114 Chitosan hydrochloride (CL113, $110 \mathrm{kDa}, 86 \%$ deacetylation degree) was purchased from Pronova Biopolymer 115 (Norway). Doxorubicin hydrochloride (DOX, 98.0-102.0\%), sodium tripolyphosphate (TPP, 85.0\%) and sodium 
116 dodecyl sulphate (SDS, $\geq 99.0 \%$ ) were obtained from Sigma-Aldrich. Reagents for Alamar Blue ${ }^{\circledR}$ and 3-[4,5-

117 dimethylthiazol-2-yl]-2,5-diphenyltetrazolium bromide (MTT) assays, as well as cell culture media and

118 supplements and trypsin solution were purchased from Biosciences (Ireland). Ultrapure water used for all

119 experiments was obtained from a Milli-Q water purification system (Millipore Co., USA).

120

\section{Preparation of chitosan nanoparticles}

123 Chitosan nanoparticles (CS-TPP) were prepared by ionotropic gelation [15]. Pre-formulation studies were

124 performed to obtain chitosan nanoparticles with adequate amounts of each component, according to the methods 125 described previously [14,16], with some modifications. Briefly, $21 \mathrm{mg}$ of CS were dissolved in $10 \mathrm{~mL}$ of $1 \%$ 126 acetic acid (pH 4.8 adjusted with $2 \mathrm{M} \mathrm{NaOH}$ solution) and $500 \mu \mathrm{L}$ of this solution were mixed with $10 \mu \mathrm{L}$ of 10 $127 \mathrm{mg} / \mathrm{mL}$ sodium dodecyl sulphate (SDS) and $10 \mu \mathrm{L}$ of $10 \mathrm{mg} / \mathrm{mL}$ DOX solution (water was used for unloaded 128 nanoparticles). $100 \mu \mathrm{L}$ of a $2.9 \mathrm{mg} / \mathrm{mL}$ sodium tripolyphosphate (TPP) solution were added to the CS solution 129 under magnetic stirring, leading to the immediate formation of the nanoparticles. The suspension formed was

130 centrifuged at $1500 \times g$ for 40 min for purification, the supernatant was discarded and the pellet re-suspended in 131 water. The preparation process was performed inside a laminar flow hood. SDS was employed to counter-

132 balance the charges in the particle and enable doxorubicin $(\mathrm{pKa}=8.2)$ to be encapsulated.

\section{Physicochemical characterisation of chitosan nanoparticles}

136 Number mean diameter and particle size distribution were evaluated by dynamic light scattering and zeta 137 potential was determined by laser Doppler microelectrophoresis (Zetasizer ${ }^{\circledR}$ Nano ZS, Malvern Instruments, 138 UK). The system is routinely calibrated with NIST 3000 Series Nanosphere ${ }^{\text {TM }}$ Size Standards, available from 139 Thermo Scientific $(60 \mathrm{~nm}, 100 \mathrm{~nm}$ and $1 \mu \mathrm{m})$. Particle concentration was analysed by turbidimetry [27].

140 The method for quantification of DOX encapsulation in the DOX-CS-TPP nanoparticles used in this 141 work was UV spectrophotometry (SpectraMax ${ }^{\circledR}$ M2, Molecular Devices, USA), as it is fast, precise and has 142 good specificity [28].

\section{Quantification of doxorubicin}


146 Quantification of DOX was performed at $482 \mathrm{~nm}$ after validation of the analytical method by the determination

147 of the following parameters: specificity, linearity, repeatability and accuracy. A standard solution of $10 \mathrm{mg} / \mathrm{mL}$

148 of DOX was used, from which calibration curves of absorbance at $482 \mathrm{~nm}$ were constructed over the DOX

149 concentration range $34-311 \mu \mathrm{M}(20-180 \mu \mathrm{g} / \mathrm{mL})$. Encapsulation efficiency was calculated according to

150 equation (S1), in which Total DOX is the absorbance of the suspensions of loaded nanoparticles before

151 ultracentrifugation and Free DOX is the absorbance of the supernatant after ultracentrifugation of suspensions of

152 loaded nanoparticles at $14000 \times g$ for $10 \mathrm{~min}$ in centrifugal filter units $\left(30 \mathrm{~K}\right.$, Amicon ${ }^{\circledR}$, EMD Millipore Co.,

153 MA, USA). The results are expressed as the mean of three different batches.

154

155 Equation $(\mathrm{S} 1)$

$$
\text { DOX encapsulation efficiency }=\frac{\text { Total DoX-Free DOX }}{\text { Total DOX }}
$$

\section{Cell culture}

The A549 human alveolar adenocarcinoma cell line was obtained from ATTC (Manassas, USA) and employed

160 for cytotoxicity evaluations. Cells were cultured in Dulbecco's Modified Eagle's Medium (DMEM) F-12,

161 supplemented with $10 \%$ foetal bovine serum (FBS), $45 \mathrm{UI} / \mathrm{mL}$ penicillin and $45 \mu \mathrm{g} / \mathrm{mL}$ streptomycin, and kept in humidified incubator at $37^{\circ} \mathrm{C}\left(5 \% \mathrm{CO}_{2}\right)$.

\section{Cytotoxicity studies}

\section{5}

166 Cells were seeded in 96-well plates at densities of $1 \times 10^{5}, 7 \times 10^{4}$ and $3 \times 10^{4}$ cells $/ \mathrm{mL}$ for 24,48 and $72 \mathrm{~h}$ of exposure, respectively. Cells were allowed to attach for $24 \mathrm{~h}$ and then washed with phosphate buffered saline

168 (PBS) prior to treatment with fresh medium containing unloaded chitosan nanoparticles (CS-TPP), solutions of doxorubicin in water (free DOX) or doxorubicin-loaded chitosan nanoparticles (DOX-CS-TPP) in the concentration range $1.5 \times 10^{-4}-7.6 \mu \mathrm{M}\left(8.8 \times 10^{-5}-4.4 \mu \mathrm{g} / \mathrm{mL}\right)$ of DOX. CS-TPP results are expressed in particles $/ \mathrm{mL}\left(1 \times 10^{7}-5 \times 10^{11}\right.$ particles $/ \mathrm{mL}$, as calculated by turbidimetry $)$. After the requisite exposure time,

172 cell viability was measured by MTT and AB assays in accordance with manufacturer's instructions.

\section{3}

\section{$174 \quad$ Live cell imaging}


178 A549 cells were seeded in glass bottom Petri dishes at a density of $1 \times 10^{4}$ cells/dish in DMEM F-12 medium supplemented with $10 \% \mathrm{FBS}$, and kept in a humidified incubator at $37^{\circ} \mathrm{C}\left(5 \% \mathrm{CO}_{2}\right)$. Cells were allowed to

180 attach for $24 \mathrm{~h}$, washed with PBS and exposed to $7.6 \mu \mathrm{M}(4.4 \mu \mathrm{g} / \mathrm{mL})$ of free DOX or $5 \times 10^{11}$ particles $/ \mathrm{mL}$ of

181 CS-TPP and DOX-CS-TPP (as calculated by turbidimetry) or fresh medium as a negative control, and incubated

182 for $24 \mathrm{~h}$. After the requisite exposure time, cells were washed three times with pre-warmed PBS $\left(37^{\circ} \mathrm{C}\right)$.

183 Hoechst 33342 stain solution (initial concentration of $20 \mathrm{mM}$ ), used for DNA and nucleus staining of eukaryotic

184 cells, was diluted 2000 times in PBS and cells were stained for $10 \mathrm{~min}$. Before imaging, cells were washed three 185 times with PBS to assure complete removal of non-internalised stain. Images were obtained through the 186 software AxioVision (version 4.8.1.0, Carl Zeiss Imaging Solutions Gmbh, Germany), annexed to an inverted microscope for transmitted light and epifluorescence Axiovert 200M (Carl Zeiss, Germany), equipped with

188 AxioCamHR camera. Brightfield settings with 63x objective, as well as DAPI (blue) and DsRed (red) filters were used for imaging.

Confocal microscopy

A549 cells were seeded in glass bottom Petri dishes at a density of $1 \times 10^{4}$ cells/dish in DMEM F-12 medium

194 supplemented with $10 \% \mathrm{FBS}$, and kept in a humidified incubator at $37{ }^{\circ} \mathrm{C}\left(5 \% \mathrm{CO}_{2}\right)$. Cells were allowed to attach for 24h, washed with PBS and subjected to early endosomal staining (Cell Light Early Endosomes-RFP, BacMam 2.0, $30 \mathrm{ppc})$ for $16 \mathrm{~h}$. After this period, cells were exposed to $7.6 \mu \mathrm{M}(4.4 \mu \mathrm{g} / \mathrm{mL})$ of free DOX or $5 \times$ $10^{11}$ particles/mL of CS-TPP and DOX-CS-TPP (as calculated by turbidimetry) or fresh medium as negative control, and incubated for $4 \mathrm{~h}$. After exposure for the appropriate time, cells were washed three times with prewarmed PBS $\left(37^{\circ} \mathrm{C}\right)$, to ensure complete removal of non-internalised stain. Images were obtained through confocal fluorescence microscope LSM 510 META (version 3.2 SP2, Carl Zeiss, Germany), using fixed excitation wavelength at $488 \mathrm{~nm}$ and fluorescence detection was achieved with a 505-530 nm band pass filter (green) and a $585 \mathrm{~nm}$ long pass filter (red). 
206 All experiments were carried out in triplicate (three independent experiments). MTT and AB assays results are

207 expressed as mean percentage relative to unexposed control \pm standard deviation (SD), wherein unexposed

208 control values were considered 100\%. Differences among groups were statistically analysed through the

209 software GraphPad Prism (version 5.0, GraphPad Software, Inc., USA), and a $p$-value $<0.05$ was considered

210 significant. Data normality was confirmed by the Kolmogorov-Smirnov test and the homogeneity of variances

211 was evaluated using the Bartlett test. One-way ANOVA followed by Bonferroni's post-test was employed for

212 data with normal distribution and homogeneous variances. Non-parametric Kruskal-Wallis test followed by

213 Dunn's post-test was applied to samples without normal distribution and/or inhomogeneous variances.

214 Cytotoxicity data were adjusted to a sigmoidal curve through the software SigmaPlot ${ }^{\mathrm{TM}}$ (version 10.0, Systat

215 Software, Inc., USA) and a four-parameter model (Eq. 1) was used to calculate the effective nanomaterial

216 concentration that caused $50 \%$ of the maximum observed inhibition compared to unexposed controls $\left(\mathrm{EC}_{50}\right)$.

$217 \quad$ Equation (1) $\quad \mathrm{y}=\min +\frac{\max -\min }{1+\left(\frac{\mathrm{x}}{\mathrm{EC50}}\right)^{\mathrm{Hills}} \mathrm{ilope}}$

218 Numerical simulations were performed by integration using the iterative Euler approach [29] and SigmaPlot ${ }^{\mathrm{TM}}$

219 (v.10.0) was used to generate the values and graphs.

220

\section{$221 \quad$ Results}

\section{Preparation and physicochemical characterisation of chitosan nanoparticles}

225 The characterisation results for size distribution, surface charge and particle concentration of chitosan

226 nanoparticle suspensions are listed in Table 1. The number size distribution of unloaded (CS-TPP) and

227 doxorubicin-loaded (DOX-CS-TPP) nanoparticles is illustrated in Online Resource 1 (Figure S1).

228 In order to quantify the encapsulation of DOX, calibration curves were constructed by plotting absorbance

229 versus DOX concentration over the range $34-311 \mu \mathrm{M}$. The least squares method was applied for linear

230 regression analysis and the calculated value for the correlation coefficient $\left(r^{2}=0.9996\right)$ showed excellent

231 linearity of the calibration curve, with no significant deviation from linearity. The specificity was determined by

232 the absorption spectrum of CS-TPP formulations, in comparison with the absorption spectra of free DOX and

233 DOX added to CS-TPP (Online Resource 1, Figure S2). The absorbance of CS-TPP was determined to be

2340.0128 at $482 \mathrm{~nm}$, thus achieving good selectivity towards DOX, without any potential interference from the

235 formulation. 
Repeatability (inter-day precision) was studied by calculating the relative standard deviation (RSD) for

237 three independent determinations of three different concentrations, from which a value of RSD $<5 \%$ was

238 obtained. In addition, the accuracy of the analytical method, which is the closeness of the test results obtained

239 by the method to the true value, was calculated by three replicate determinations of concentrations of 34,145

240 and $256 \mu \mathrm{M}$ in the presence of CS-TPP. The results showed that the proposed method has an accuracy of 103.9

$241 \pm 2.0 \%$ within the desired range.

242 In this way, the DOX concentration in DOX-CS-TPP formulations was determined to be $76 \pm 7 \mu \mathrm{M}$ by

243 direct absorbance determination, and the encapsulation efficiency after purification was $95 \pm 1 \%$, according to

244 absorbance determination of the supernatant. Thus, a DOX-CS-TPP concentration of 1 particle/mL corresponds

245 to a dose of $8.29 \pm 0.92 \times 10^{-12} \mu \mathrm{M}$.

\section{Cytotoxicity studies}

249 Figure 1 illustrates the dose dependent cytotoxic responses for both MTT and AB at 24, 48 and $72 \mathrm{~h}$. For both 250 assays, a significant dose dependent response is observed, the loss of viability increasing with increasing dose 251 and exposure time. Notably, the MTT is somewhat more responsive to the DOX exposure, particularly at shorter 252 exposure times. For the case of CS-TPP nanoparticles, a significant toxic response is also observed (40.6 $\pm 4.2 \%$ 253 and $77.0 \pm 9.0 \%$ viability, MTT and AB respectively, at $5 \times 10^{11}$ particles $/ \mathrm{mL}$ at $48 \mathrm{~h}$ ), although for equivalent 254 exposure times, the response for both assays is considerably lower over the exposure range, compared to the 255 free DOX exposure range (Figure 1A and B). As is the case for free DOX, MTT is seen to be a more sensitive 256 assay than $\mathrm{AB}$ (Figure $1 \mathrm{C}$ and $\mathrm{D})\left(\mathrm{EC}_{50}\right.$ of $0.38 \pm 0.08$ and $0.93 \pm 0.29 \mu \mathrm{M}$ of DOX for MTT and $\mathrm{AB}$, 257 respectively, at 24h). When exposed to DOX loaded chitosan nanoparticles, DOX-CS-TPP (Figure 1E and F), 258 over the same nanoparticle exposure dose range, a stronger toxic response (difference Max - Min viability of 259111.8 and 109.7 for MTT and AB, respectively, at 72h) is elicited than for unloaded CS-TPP nanoparticles 260 (difference Max - Min viability of 64.2 and 10.8 for MTT and AB, respectively, at 72h), indicating some degree 261 of success in the intracellular delivery of the chemotherapeutic agent encapsulated as cargo in the nano drug 262 delivery vehicle. Over the same equivalent DOX dose range, however, the toxic response appears weaker, at 263 least at the shorter exposure time of $24 \mathrm{~h}$ (at the higher dose, DOX elicits $35.0 \pm 14.4 \%$ and $55.8 \pm 16.3 \%$ 264 viability, while DOX-CS-TPP elicits $48.1 \pm 6.6 \%$ and $81.6 \pm 6.0 \%$ viability, for MTT and AB, respectively), 265 indicating a reduced intracellular rate of delivery of DOX. 
The lines of Figure 1 show fits of equation 1 to the respective experimental data. The associated fit parameters are tabulated in Table S1 (Online Resource 1). In general, a trend of decreasing $\mathrm{EC}_{50}$ with increasing exposure time reflects the increasing toxic response, and the relatively lower values for MTT compared to AB for each exposure time reflects the higher sensitivity of that assay. Of particular relevance is the comparison of

270 the $\mathrm{EC}_{50}$ values for free DOX exposure compared to the equivalent DOX values for the DOX-CS-TPP exposures, which, for both $\mathrm{MTT}$ and $\mathrm{AB}$, reveal a considerably higher $\mathrm{EC}_{50}$ dose equivalent for the latter $(\mathrm{AB}$

$272 \mathrm{EC}_{50}$ of $0.26 \pm 0.06$ and $0.07 \pm 0.02 \mu \mathrm{M}$ of DOX for DOX-CS-TPP and free DOX, respectively, at 72h).

\section{$274 \quad$ Live cell imaging}

Firstly, cells were observed using fluorescent microscopy, after incubation for $24 \mathrm{~h}$ with test suspensions and the

277 Hoechst 33342 blue stain for the nucleus. Red fluorescence imaging was used to visualize DOX. Figure 2 shows

278 that the red fluorescence in the cells exposed to free DOX is concentrated in the nucleus. In comparison, cells

279 exposed to DOX-CS-TPP show less co-localization of the red fluorescence with the nuclear stain. investigate the cellular uptake behavior by confocal laser scanning microscopy (CLSM), after early endosomal staining. As shown in Figure 3, the green fluorescence of the endosomal stain was observed in all the cells, independent of the treatment, showing successful staining of early endosomes. After exposure to unloaded CS-

284 TPP nanoparticles, the endosomal staining is concentrated in small vesicles, distributed throughout the cytoplasm, consistent with uptake of the nanoparticles into early endosomes [30]. Furthermore, the intracellular

286 DOX can be identified by the red fluorescence, which is observed predominantly in the nuclei for free DOX treated cells. For DOX-CS-TPP treated cells, DOX fluorescence is also present in the cytoplasm, corroborating the fluorescence microscopy images, and indicates its localization in early endosomes (yellowish color), as well as in other subcellular compartments.

\section{Numerical simulations using rate equation model}

293 The cellular uptake of, and responses to, the external agents can be numerically simulated in order to further

294 elucidate the different responses. Such an approach, based on a rate equation model, has previously been 
employed to simulate the time and dose dependent cytotoxicity of polymeric dendrimer nanoparticles, as well as the observed differences in responses for different cytotoxic assays and cell lines [23,31]. order rate equation:

$$
\frac{\mathrm{dN}_{\text {DOX }}}{\mathrm{dt}}=\mathrm{k}_{\mathrm{DOX}}\left(\mathrm{D}-\mathrm{N}_{\mathrm{DOX}}\right)
$$

where $\mathrm{N}_{\text {DOx }}$ is the dose of internalised DOX and $\mathrm{k}_{\text {DOX }}$ is the rate of internalisation. The term (D-N $\mathrm{N}_{\text {DOX }}$ ) allows for depletion of the applied dose by the uptake process. The accepted mode of action of DOX, once internalised, is the rapid localisation in the nucleus, in which it intercalates with DNA, resulting in the onset of apoptosis

303 [32]. In the formalism of Black and Leff [33], the DOX binds with receptors, according to the equation:

$304 \quad$ Equation (3)

$$
\frac{\mathrm{dN}_{\mathrm{RB}}}{\mathrm{dt}}=\mathrm{k}_{\mathrm{RB}} \mathrm{N}_{\mathrm{DOX}}\left(\mathrm{N}_{\mathrm{Rmax}}-\mathrm{N}_{\mathrm{RB}}\right)
$$

where $\mathrm{N}_{\mathrm{RB}}$ is the number of bound receptors, $\mathrm{k}_{\mathrm{RB}}$ is the receptor binding rate, and $\mathrm{N}_{\mathrm{Rmax}}$ is the maximum number of available receptors. The MTT assay reveals changes in mitochondrial activity, which, as a result of the action of DOX in the nucleus and the onset of apoptosis, can be modelled according to:

$$
\frac{\mathrm{dMTT}}{\mathrm{dt}}=\mathrm{MTT}_{\max }-\mathrm{k}_{\mathrm{MTT}} \text { MTT. } \mathrm{N}_{\mathrm{RB}}
$$

where MTT is the response of the assay as a function of time, $\mathrm{MTT}_{\max }$ being the maximum at zero exposure, and $\mathrm{k}_{\mathrm{MTT}}$ is the rate of response of the mitochondria as a result of the nuclear insult of DOX.

Equations (2-4) can be solved numerically, generating a time dependence of the cellular uptake of and response to DOX exposure, over the dose range. Figures 4A and B show the simulated dose dependent response 313 for the time points of 24, 48 and $72 \mathrm{hrs,} \mathrm{as} \mathrm{compared} \mathrm{to} \mathrm{the} \mathrm{experimentally} \mathrm{determined} \mathrm{responses} \mathrm{of} \mathrm{Figure} \mathrm{1.} \mathrm{A}$ list of fit parameters is provided in the Online Resource 1. As shown in Figure 4C, for $0.1 \mu \mathrm{M}$ dose, a rapid uptake of DOX and binding to the nuclear receptors is followed by a slower response of the mitochondrial activity. The dose dependent responses at the experimentally measured time points are well reproduced by the simulation based on the rate equation model.

For the case of the $\mathrm{AB}$ response, the experimental results are not well simulated by either a cascade of

$319 \mathrm{AB}$ response, triggered by the MTT response of Equation 4, or even the $\mathrm{AB}$ response triggered by the nuclear receptor binding described by Equation 3. Instead, the closest simulation of the experimental observations was achieved by providing an alternative route of intracellular interaction of the internalised DOX molecules. In addition to the mode of action of DNA intercalation, internalised DOX can also lead to the generation of free 
323 radicals, resulting in DNA and cell membrane damage [34]. The response can be simulated such that, after

324 uptake according to Equation 2, the DOX interacts according to:

325

Equation (5)

$$
\frac{\mathrm{dN}_{\mathrm{FR}}}{\mathrm{dt}}=\mathrm{k}_{\mathrm{FR}} \mathrm{N}_{\mathrm{DOX}}^{0.5}\left(\mathrm{~N}_{\mathrm{FRmax}}-\mathrm{N}_{\mathrm{FR}}\right)
$$

where $\mathrm{N}_{\mathrm{FR}}$ is the number of generated free radicals, $\mathrm{k}_{\mathrm{FR}}$ is the radical generation rate, and $\mathrm{N}_{\mathrm{FRmax}}$ is the maximum number of free radicals which can be generated. The square root dependence on $\mathrm{N}_{\mathrm{DOX}}$ is indicative of a cascade process of one DOX molecule resulting in two or more radicals. The AB assay registers changes in cytoplasmic activity, which, as a result of the action of DOX in the cytoplasm, can be modelled according to:

330 Equation (6)

$$
\frac{\mathrm{dAB}}{\mathrm{dt}}=\mathrm{AB}_{\max }-\mathrm{k}_{\mathrm{AB}} \mathrm{AB} \cdot \mathrm{N}_{\mathrm{FR}}
$$

331 where $\mathrm{AB}$ is the response of the assay as a function of time, $\mathrm{AB}_{\max }$ being the maximum at zero exposure, and $\mathrm{k}_{\mathrm{AB}}$ is the rate of response of the cytoplasmic activity as a result of the insult of DOX. Figure $5 \mathrm{~B}$ shows the simulated $\mathrm{AB}$ response to the DOX exposure, compared to the experimentally observed responses. As shown in Figure $4 \mathrm{C}$, the $\mathrm{AB}$ response (at a dose of $0.1 \mu \mathrm{M}$ ) is slower than that of the MTT, resulting in lower cytotoxic responses at the respective time and dose points. and dose, can similarly be simulated. For a dose D, the uptake of CS-TPP within the cells can be described by the first order rate equation:

Equation (7)

$$
\frac{\mathrm{dN}_{\mathrm{NP}}}{\mathrm{dt}}=\mathrm{k}_{\mathrm{NP}}\left(\mathrm{D}-\mathrm{N}_{\mathrm{NP}}\right)
$$

where $\mathrm{N}_{\mathrm{NP}}$ is the dose of internalised CS-TPP nanoparticles and $\mathrm{k}_{\mathrm{NP}}$ is the rate of internalisation. The term (D-

$341 \mathrm{~N}_{\mathrm{NP}}$ ) allows for depletion of the applied dose by the uptake process. As shown in Figure 3, using CLSM, the nanoparticles are endocytosed and the common mechanism of toxicity is further trafficking through lysosomes

343 and the generation of oxidative stress, resulting in cell damage and apoptosis [35]. Following the approach of

344 Maher et al. [23], the cellular response is the result of an interaction of the endocytosed nanoparticles with an

345 intracellular source of reactive oxygen species (ROS), $\mathrm{N}_{\text {source }}$, which is depleted by the ROS generation process.

346 Thus,

347 Equation (8)

$$
\frac{\mathrm{dN}_{\text {Source }}}{\mathrm{dt}}=-\mathrm{k}_{\mathrm{A}} \cdot \mathrm{N}_{\mathrm{NP}} \mathrm{A} \cdot \mathrm{N}_{\text {Source }}
$$

348 where $\mathrm{k}_{\mathrm{A}}$ is the interaction rate for the nanoparticles and source, and $\mathrm{A}$ is an empirical constant. The generation 349 of ROS is then described by:

350 Equation (9)

$$
\frac{\mathrm{dN}_{\mathrm{ROS}}}{\mathrm{dt}}=-\mathrm{k}_{\mathrm{A}} \cdot \mathrm{N}_{\mathrm{NP}} \cdot \mathrm{N}_{\text {Source }}-\mathrm{k}_{\mathrm{q}} \cdot \mathrm{N}_{\mathrm{ROS}} \cdot \mathrm{N}_{\mathrm{GSH}}
$$


351 The second term of Equation (9) describes the quenching of the ROS at a rate $k_{q}$, and depends on both; ROS

352 levels, $\mathrm{N}_{\mathrm{ROS}}$, and antioxidant levels, $\mathrm{N}_{\mathrm{GSH}}\left(\mathrm{N}_{\mathrm{GSH}}(0)=0\right)$. In the study by Mukerjee and Byrne [31], the

353 antioxidant levels were represented by the experimentally measured values of glutathione (GSH) which are

354 represented by:

355 Equation (10)

$$
\frac{\mathrm{dN} \mathrm{N}_{\mathrm{GSH}}}{\mathrm{dt}}=\mathrm{k}_{\mathrm{GSH}}-\mathrm{N}_{\mathrm{ROS}}(\mathrm{t}) \cdot \mathrm{N}_{\mathrm{GSH}}(\mathrm{t}) \cdot \mathrm{k}_{\mathrm{q}}
$$

For both MTT and AB, the loss of viability is represented by equations (4) and (6), replacing $\mathrm{N}_{\mathrm{RB}}$ or

$357 \mathrm{~N}_{\mathrm{FR}}$ by $\mathrm{N}_{\mathrm{ROS}}$ and nanoparticle specific rate constants $\mathrm{k}_{\mathrm{MTT}}{ }$ and $\mathrm{k}_{\mathrm{AB}}$. The resultant simulated plots of dose

358 dependent viability for the time points of 24, 48 and 72 hrs are shown in Figure 5 (A) MTT, and (B) AB. The fit

359 parameters are provided in the Online Resource 1. The simulations satisfactorily reproduce the trends observed

360 experimentally. A notable difference between the simulations for DOX and CS-TPP is the rate of uptake of the

361 respective agent by the cells, as shown in Figure 5C, which is substantially slower for the nanoparticles than for

362 the molecular species, $\left(\mathrm{k}_{\mathrm{DOX}}=2 \mathrm{hr}^{-1}, \mathrm{k}_{\mathrm{NP}}=0.5 \mathrm{hr}^{-1}\right)$ consistent with the observations of Salvati et al. [30] for

363 polystyrene nanoparticles uptake compared to free organic fluorescent dye molecules.

364 To simulate the cytotoxic responses to the nanoparticle encapsulated DOX, the DOX-CS-TPP uptake

365 was simulated according to Equation (7), and subsequent responses to the endocytosed nanoparticles were

366 evaluated according to Equations (8-10), in all cases using the same fit parameters as for CS-TPP (Online

367 Resource 1). As shown in Figure 3, however, once endocytosed, the DOX-CS-TPP release the DOX into the

368 cytosol, from where it reaches the nucleus. The process is simulated according to the equation:

369 Equation (11)

$$
\frac{\mathrm{dN}_{\mathrm{DOX}}}{\mathrm{dt}}=\mathrm{k}_{\mathrm{R}} \cdot \mathrm{N}_{\mathrm{NP}}
$$

370 where $k_{R}$ denotes the rate of release of DOX from the endosomes. The value of $k_{R}$ incorporates the scaling

371 factor of the encapsulation efficiency. The released DOX can then interact with the cell, as described by

372 Equations (3-6). In a simple approximation, the combined effect of the CS-TPP nanoparticles and the released

373 DOX can be taken to be a linear combination, such that the viability of the cell, as measured by the MTT and

$374 \quad \mathrm{AB}$ assays, respectively, can be represented by:

375 Equation (12)

$$
\frac{\mathrm{dMTT}}{\mathrm{dt}}=\mathrm{MTT}_{\max }-\mathrm{k}_{\mathrm{MTT}} \mathrm{MTT} \cdot \mathrm{N}_{\mathrm{RB}}-\mathrm{k}_{\text {MTT }}^{\prime} \text { MTT. } \mathrm{N}_{\mathrm{ROS}}
$$

376 Equation (13)

$$
\frac{d A B}{d t}=A B_{\text {max }}-k_{A B} A B \cdot N_{F R}-k_{A B}^{\prime} A B \cdot N_{R O S}
$$

377 For both MTT and AB, k and k' indicate the rates of the two independent routes towards cell death, elicited by

378 the DOX and CS-TPP nanoparticles respectively. The simulations of Figure 6 provide a reasonable reproduction

379 of the experimental observations for the MTT and AB responses at 24, 48 and $72 \mathrm{hrs,} \mathrm{although} \mathrm{deviations} \mathrm{may}$ 
be an indication of a more complex release process of DOX from the CS-TPP nanoparticles, and subsequently from the endosomes, or a co-operative or even competing effect of the two toxicants.

Figure 7 provides a visualisation of the time dependence of the DOX-CS-TPP nanoparticle uptake and different cellular responses. It is clear that, for both MTT and AB, the loss of viability due to the toxic response to the nanoparticles is substantial (NP Response), although more significantly so for MTT than for AB. Notably, the DOX response, for both assays is delayed significantly compared to the response to the free DOX (Figure 4C), due to the delayed release of the API from the nanoparticles, encapsulated within the intracellular endosomes/lysosomes.

\section{Discussion}

In the present work, chitosan (CS) was ionically cross-linked with the counter-ion sodium tripolyphosphate

392 (TPP) through ionotropic gelation, in which positive and negative groups of each component interact to form

393 hydrogel nanoparticles [15]. The results show that, for both CS-TPP and DOX-CS-TPP nanoparticles,

394 monomodal and nanometric distributions $(220-1106 \mathrm{~nm})$ were obtained. Zeta potential values demonstrate the 395 positive characteristic of the particle surface charge, even in the presence of SDS. Furthermore, suspensions 396 presented adequate polydispersity index and particle concentration for nanoscale formulations [27]. Besides, the 397 overall results of the determination of validation parameters analysed demonstrated the adequacy of the proposed method for quantification of DOX [36].

The synthesized chitosan nanoparticles loaded with the API doxorubicin were used in this study to

400 elucidate the cytotoxicity and internalization profiles in A549 cells. A variety of endpoints are commonly used

401 to evaluate cytotoxic responses of cell lines in vitro. Each cytotoxicity assay measures a different response or 402 adjacent cell function. The Alamar Blue ${ }^{\circledR}$ assay is based on fluorescence, which indicates the innate cellular 403 metabolic activity by the conversion of resazurin (non fluorescent) in resorufin (fluorescent) [37], while the 404 MTT assay indicates mainly mitochondrial metabolism [38]. The in vitro toxicity is expressed as the effective 405 concentration for reduction of $50 \%$ of cell viability $\left(\mathrm{EC}_{50}\right)$, which is essentially the midway concentration 406 between minimum and maximum responses. The $\mathrm{EC}_{50}$ values for A549 cells found in this work for free DOX 407 are comparable with other studies [39-41], ranging from 0.5 to $5 \mu \mathrm{M}$. Notably, however, unless minimum and 408 maximum responses are close for different test substances/formulations, $\mathrm{EC}_{50}$ values are difficult to compare 409 among the variety of cell lines, assays employed and nanoparticle characteristics [22,23]. 
In order to further understand the differences in cytotoxic responses to the free API and the API loaded

411 in the nanoparticles, it is necessary to image the localization of the drug within the cells. Live cell imaging was

412 carried out following $4 \mathrm{~h}$ or $24 \mathrm{~h}$ exposure to CS-TPP, free DOX or DOX-CS-TPP, or fresh medium as negative

413 control. The fluorescence microscopy observations indicate that DOX localizes in the nucleus to a greater extent

414 when in free form compared to the DOX confined in nanoparticles, which may imply that the internalization

415 process of nanoparticles, when compared to the free drug, occurs through a different and/or slower mechanism.

416 However, due to limited resolution of this technique, it was not entirely clear whether the nanoparticles released

417 DOX on the surface of the cells or whether they were internalized into the cells.

418 In this way, we performed confocal laser scanning microscopy (CLSM) in order to better visualize the

419 DOX localization within the cells. Our results clearly indicate that DOX-CS-TPP nanoparticles are taken up by

420 the cell mostly through endocytosis and DOX is released to the nucleus afterwards, in contrast to free DOX,

which is transported into cells via passive diffusion $[41,42]$ after which it is rapidly localized within the nucleus.

Different cell uptake mechanisms of free drugs and drug-loaded nanoparticles are widely described in

423 scientific literature [43-45]. In particular, doxorubicin is useful for these studies due to its pronounced red

424 fluorescence. It is hypothesized that the acidic environment of endosomal/lysosomal compartments helps the release of DOX from nanoparticles, reaching the nucleus thereafter [45]. The delayed release of DOX, reducing

426 the overall cytotoxicity, might be beneficial depending on the ultimate effect in the cell. In order to elucidate these potentially different underlying subcellular responses, numerical simulations from cytotoxicity assays data 428 were performed.

429 Numerical simulations, based on a rate equation model to describe the uptake and distribution of the 430 free DOX, nanoparticles and DOX loaded nanoparticles within the cells, and the subsequent dose and time 431 dependent cytotoxic responses, are used to further elucidate the API distribution processes. The study 432 demonstrates that encapsulation of the API in nanoparticles results in a delayed release of the drug to the cell, 433 resulting in a delayed cellular response. Moreover, unloaded nanoparticles also displayed a degree of toxicity 434 that may indicate that DOX-CS-TPP cytotoxicity occurs through different cell death mechanisms, which in turn 435 can potentiate the cellular responses. These have been independently modelled for the free DOX and pristine 436 CS-TPP nanoparticles, and the mechanisms combined in the model for the DOX-CS-TPP toxic response for 437 both assays. As discussed in the introduction, encapsulation of APIs in nanoparticle delivery vehicles has 438 several potential advantages for clinical treatments: the passive targeting of specific tissues or cells, release of the API in a controlled manner, reduction of the necessary dose and/or number of administrations, thereby 
440 reducing potential side effects, ultimately improving efficacy and patient compliance $[2,46]$. The cellular

441 internalization of chitosan nanoparticles and the retention of encapsulated DOX bioactivity have been

442 demonstrated [11,14]. However, no previous reports have investigated unloaded and DOX-loaded chitosan

443 nanoparticles of approximately $500 \mathrm{~nm}$ in such depth. This study demonstrates that DOX encapsulated within

444 chitosan nanoparticles, although they are engulfed in endosomal vesicles, remains bioavailable and elicits a

445 toxic response in the cells, in vitro, in a similar fashion to the free API. Endoscytosis of the nanoparticles

446 containing API results, however, in a delayed release of the drug to the cell, resulting in a delayed cellular

447 response which could be potentially further controlled by tailoring the physicochemical properties of the

448 nanoparticle.

449 In summary, unloaded and doxorubicin-loaded chitosan nanoparticles were successfully synthesized

450 and physicochemically characterized for further use in in vitro experiments. This work sheds new light on the

451 differences of cellular internalization of free or encapsulated APIs, the latter having a delayed response.

452 Although free doxorubicin elicited a stronger response in comparison to doxorubicin-loaded chitosan

453 nanoparticles, such a delayed release of the drug from the nanoparticles to the cell. This effect results in similar

454 in vitro efficacy in the time frame of the cytotoxicity experiment, but may have different implications in an in

455 vivo system. For example, it may overcome partially or completely the development of tumour resistance during

456 chemotherapy, or it may show a better selectivity towards cancerous cells in comparison to non-cancerous cells.

457 These hypotheses should be addressed in future studies. We further demonstrated the potential of mathematical

458 modelling to visualise and better understand the intracellular mechanisms of action of external agents, both APIs

459 and nanoparticles in cells. DOX itself is a well-known anticancer agent that triggers tumor resistance and

460 cardiotoxicity during chemotherapy. Its selectivity towards carcinogenic and non-carcinogenic cells is low [39],

461 however, and ultimately, improved selectivity of nanoformulations, potentially by adding additional cell

462 targeting functionalities [47,48], should be demonstrated. DOX is usually administered intravenously, but

463 nanoparticles can be administered intravenously or through the pulmonary route in liquid or powder form.

464 Although, a full study of the metabolisation of DOX and of the stability of the nanoparticles, administered

465 according to established clinical protocols is beyond the scope of the present work, comparative in vitro/in vivo

466 studies must be conducted in order to fully demonstrate mathematical modelling as a viable alternative to the

467 experimentally testing of nanoparticles.

468

469 Acknowledgements 
470

471 This research was carried out under funding by the Brazilian National Council for Scientific and Technological

472 Development (CNPq), through the Science without Borders Program grant \#236817/2013-2, awarded to GDS.

473 ZF, AC, EE, JMcI and HJB are supported by Science Foundation Ireland Principle Investigator Award

474 11/PI/1108.

475

\section{Conflict of Interest}

477

478 The authors declare that they have no conflict of interest.

479

\section{$480 \quad$ References}

481

482

1. Moghimi SM, Hunter AC, Murray JC. Nanomedicine: current status and future prospects. FASEB J.

483 2005;19:311-30.

484

2. Schütz CA, Juillerat-Jeanneret L, Mueller H, Lynch I, Riediker M. Therapeutic nanoparticles in clinics and 485 under clinical evaluation. Nanomedicine-UK. 2013;8:449-67.

486

3. Oberdörster G, Oberdörster E, Oberdörster J. Nanotoxicology: an emerging discipline evolving from studies of ultrafine particles. Environ Health Persp. 2005;113:823-39.

488

4. Octavia Y, Tocchetti CG, Gabrielson KL, Janssens S, Crijns HJ, Moens AL. Doxorubicin-induced cardiomyopathy: from molecular mechanisms to therapeutic strategies. J Mol Cell Cardiol. 2012;52:121325.

5. Goldstein LJ, Galski H, Fojo A, Willingham M, Lai SL, Gazdar A, Pirker R, Green A, Crist W, Brodeur GM, Lieber M, Cossman J, Gottesman MM, Pastan I. Expression of multidrug resistance gene in human cancers. J Natl Cancer Inst. 1989;81:116-24.

494 6. Von Hoff D, Rozencweig M, Piccart M. The cardiotoxicity of anticancer agents, Semin Oncol. 1982;9:2333.

496 7. Primeau AJ, Rendon A, Hedley D, Lilge L, Tannock IF. The distribution of the anticancer drug 497 doxorubicin in relation to blood vessels in solid tumors. Clin Cancer Res. 2005;11:8782-8.

8. Hofheinz RD, Gnad-Vogt SU, Beyer U, Hochhaus A. Liposomal encapsulated anticancer drugs. Anticancer Drugs. 2005;16:691-707. 
500 9. Manil L, Couvreur P, Mahieu P. Acute renal toxicity of doxorubicin (adriamycin)-loaded cyanoacrylate $501 \quad$ nanoparticles. Pharm Res. 1995;12:85-7.

502 10. Lorusso D, Di Stefano A, Carone V, Fagotti A, Pisconti S, Scambia G. Pegylated liposomal doxorubicinrelated palmar-plantar erythrodysesthesia ('hand-foot' syndrome). Ann Oncol. 2007;18:1159-64.

504 11. Tan ML, Choong PFM, Dass CR. Review: doxorubicin delivery systems based on chitosan for cancer therapy. J Phar Pharmacol. 2009;61:131-42.

506 12. Siqueira NM, Contri RV, Paese K, Beck RCR, Pohlmann AR, Guterres SS. Innovative sunscreen formulation based on benzophenone-3-loaded chitosan-coated polymeric nanocapsules. Skin Pharmacol Physiol. 2011;24:166-74.

13. Nafee N, Schneider M, Schaefer UF, Lehr CM. Relevance of the colloidal stability of chitosan/PLGA nanoparticles on their cytotoxicity profile. Int J Pharm. 2009;381:130-9.

14. Janes KA, Fresneau MP, Marazuela A, Fabra A, Alonso MJ. Chitosan nanoparticles as delivery systems for doxorubicin. J Control Rel. 2001;73:255-67.

15. Sureshkumar MK, Das D, Mallia MB, Gupta PC. Adsorption of uranium from aqueous solution using chitosan-tripolyphosphate (CTPP) beads. J Haz Mat. 2010;184:65-72.

16. Bugnicourt L, Alcouffe $\mathrm{P}$, Ladavière C. Elaboration of chitosan nanoparticles: Favorable impact of a mild thermal treatment to obtain finely divided, spherical, and colloidally stable objects. Col Surf A.

518 17. European Commission. Definition of Nanoparticle. In: Scientific Committees Toolbox. Scientific Committee on Emergent and Newly Identified Health Risks. 2007. http://ec.europa.eu/health/scientific_committees/opinions_layman/glossary/mno/nanoparticle.htm.

522 18. International Organisation for Standardization. In: Technical Committee 229 Nanotechnologies (ISO/TC 229). 2005. http://www.iso.org/iso/iso_technical_committee?commid=381983. Accessed 19 Apr 2016.

524 19. 17Keating M, Byrne HJ. Raman spectroscopy in nanomedicine: current status and future perspectives. Nanomedicine. 2013;8:1-17.

526 20. 18European Parliament and the Council of the European Union. Directive 2010/63/EU of the European Parliament and the Council of 22 September 2010 on the protection of animals used for scientific purposes. 
529 21. 19Huang, Y.-W.; C-H, Wu.; Aronstam, R.S. Toxicity of transition metal oxide nanoparticles: Recent $530 \quad$ insights from in vitro studies. Materials v. 3, p. 4842-4859, 2010.

531 22. 20Mukherjee SP, Davoren M, Byrne HJ. In vitro mammalian cytotoxicological study of PAMAM dendrimers - towards quantitative structure activity relationships. Toxicol In Vitro. 2010;24:169-77.

533 23. 21Maher MA, Naha PC, Mukerjee SP, Byrne HJ. Numerical simulations of in vitro nanoparticle toxicity 534 the case of Poly(amido amine) dendrimers. Toxicol in Vitro. 2014;28:1449-60.

535 24. Nawaz H, Bonnier F, Knief P, Howe O, Lyng FM, Meade AD, Byrne HJ. Evaluation of the potential of Raman Microspectroscopy for prediction of chemotherapeutic response to cisplatin in lung adenocarcinoma. Analyst. 2010;135:3070-76.

25. Nawaz H, Bonnier F, Meade AD, Lyng FM, Byrne HJ. Comparison of subcellular responses for the evaluation and prediction of the chemotherapeutic response to cisplatin in lung adenocarcinoma using Raman spectroscopy. Analyst. 2011;136:2450-63.

26. Nawaz H, Garcia A, Meade AD, Lyng FM, Byrne HJ. Raman micro spectroscopy study of the interaction of vincristine with A549 cells supported by expression analysis of bcl-2 protein. Analyst. 2013;138:617784.

27. 22Poletto FS, Jager E, Cruz L, Pohlmann AR, Guterres SS. The effect of polymeric wall on the permeability of drug-loaded nanocapsules. Mat Sci Eng C. 2008;28:472-8.

29. 24Atkinson KE. An Introduction to Numerical Analysis. 2nd ed. New York: John Wiley \& Sons, Inc.; 1989. polymeric nanoparticles and small molecules: toward models of uptake kinetics. Nanomedicine: NBM. 2011;7:818-26.

31. 26Mukherjee SP, Byrne HJ. Polyamidoamine dendrimer nanoparticle cytotoxicity, oxidative stress, caspase activation and infammatory response: experimental observation and numerical simulation.

557 32. 27Kaufmann SH, Earnshaw WC. Induction of apoptosis by cancer chemotherapy. Exp Cell Res. 
33. 28Black JW, Leff P. Operational models of pharmacological agonism. Proc R Soc Lond [Biol]. 1983;220:141-62.

34. 29Gewirtz DA. A critical evaluation of the mechanisms of action proposed for the antitumor effects of the anthracycline antibiotics adriamycin and daunorubicin. Biochem Pharmacol. 1999;57:727-41.

36. 31International Conference on Harmonisation (ICH). Validation of Analytical Procedures: Text and Methodology Q2(R1). 2005. http://www.ich.org/fileadmin/Public_Web_Site/ICH_Products/Guidelines/Quality/Q2_R1/Step4/Q2_R1_ Guideline.pdf. Accessed 15 Jul 2015.

37. 32O'Brien J, Wilson I, Orton T, Pognan F. Investigation of the Alamar Blue (resazurin) fluorescent dye for the assessment of mammalian cell cytotoxicity. Eur J Biochem. 2000;267:5421-6.

38. 33De Fries R, Mitsuhashi M. Quantification of mitogen induced human lymphocyte proliferation: Comparison of alamarbluetm assay to 3h-thymidine incorporation assay. J Clin Lab Anal. 1995;9:89-95.

39. 34Poornima P, Kumar VB, Weng CF, Padma VV. Doxorubicin induced apoptosis was potentiated by neferine in human lung adenocarcinoma, A549 cells. Food Chem Toxicol. 2014;68:87-98.

40. 35Lv S, Tang Z, Li M, Lin J, Song W, Liu H, Huang Y, Zhang Y, Chen X. Co-delivery of doxorubicin and paclitaxel by PEG-polypeptide nanovehicle for the treatment of non-small cell lung cancer. Biomaterials.

41. 36Farhane Z, Bonnier F, Casey A, Byrne HJ. Raman microspectroscopy for in vitro drug screening: subcellular localization and interactions of doxorubicin. Analyst. 2015;140:4212-23. grafted mPEG-b-PLG loaded with doxorubicin: Preparation, in vitro and in vivo evaluation. Int J Pharm. 2014;471:412-20. A549 lung cancer cells by CXCR4 antagonist conjugated PLGA nanoparticles. Eur J Pharm Biopharm. 2014;88:529-38. 
588 45. 40Wang X-B, Zhou H-Y. Molecularly targeted gemcitabine-loaded nanoparticulate system towards the treatment of EGFR overexpressing lung cancer. Biomed Pharmacother. 2015;70:123-8.

590 46. 41Uhrich KE, Cannizzaro SM, Langer RS, Shakesheff KM. Polymeric systems for controlled drug release. Chem Rev. 1999;99:3181-98.

592 47. Siddique MI, Katas H, Amin MCIM, Ng SF, Zulfakar MH, Buang F, Jamil A. Minimization of Local and Systemic Adverse Effects of Topical Glucocorticoids by Nanoencapsulation: In Vivo Safety of Hydrocortisone-Hydroxytyrosol Loaded Chitosan Nanoparticles. J Pharm Sci. 2015;104:4276-86. increase in therapeutic effect of doxorubicin, suppressing its adverse effect. J Control Rel. 2013;172:13743. 


\section{Tables}

600 Table 1. Results of physicochemical characterisation of chitosan nanoparticles.

601

\begin{tabular}{|l|c|c|}
\hline Parameter $^{\mathrm{a}}$ & CS-TPP & DOX-CS-TPP \\
\hline Number mean (nm) & $509 \pm 13$ & $473 \pm 41$ \\
\hline Polydispersity index & $0.28 \pm 0.05$ & $0.31 \pm 0.2$ \\
\hline Zeta potential (mV) & $35 \pm 4$ & $34 \pm 4$ \\
\hline Particle concentration (particles/mL) & $3.7 \pm 0.2 \times 10^{12}$ & $5.1 \pm 0.2 \times 10^{12}$ \\
\hline
\end{tabular}

${ }^{\mathrm{a}}$ Results are expressed as mean \pm SD.

602

603 Figure Legends

604 Fig. 1 Experimental (symbols) and simulated (lines) exposure time and dose dependent viability, as measured 605 using the MTT and Alamar Blue ${ }^{\circledR}(\mathrm{AB})$ assays, for A549 cells at 24, 48 and 72h. For (E) and (F) the X-axis label 606 indicates the dose $\mu \mathrm{M}$ and particles per $\mathrm{mL}$. Viability is expressed as the mean \pm S.D. of the \% decrease in 607 formazan absorbance (for MTT) or resorufin fluorescence (for Alamar Blue ${ }^{\circledR}$ ), as compared to the unexposed 608 control of three independent experiments. (A) and (B) MTT and AB of CS-TPP; (C) and (D) MTT and AB of 609 Free DOX; (E) and (F) MTT and AB of DOX-CS-TPP

610 Fig. 2 Fluorescence microscopy images of A549 cells after incubation with CS-TPP, free DOX or DOX-CS-

611 TPP for $24 \mathrm{~h}$. The arrows highlight the co-localization of red fluorescence from DOX with blue nuclear stain 612 (pinkish color) in Free DOX treated cells and predominantly less co-localization in DOX-CS-TPP treated cells

613 Fig. 3 Confocal microscopy images of A549 cells after incubation with CS-TPP, free DOX or DOX-CS-TPP for 614 4h. The arrows highlight the co-localization of DOX-CS-TPP with early endosomes (yellowish color)

615 Fig. 4 Simulated dose dependent cytotoxic responses for exposure to free DOX (A) MTT and (B) AB. (C)

616 Simulated time dependent DOX uptake and cytotoxic responses of MTT and AB at a dose of $0.1 \mu \mathrm{M}$

617 Fig. 5 Simulated dose dependent cytotoxic responses for exposure to CS-TPP (A) MTT (B) AB. (C) Simulated

618 time dependent CS-TPP nanoparticle uptake and cytotoxic responses of MTT and AB at a dose of $10^{10}$

619 particles/mL

620 Fig. 6 Simulated dose dependent cytotoxic responses for exposure to DOX-CS-TPP (A) MTT (B) AB.

621 Simulated time dependent DOX-CS-TPP uptake and cytotoxic responses of (C) MTT and (D) AB at a dose of $62210^{10}$ particles/mL $(0.1 \mu \mathrm{M}$ of DOX $)$ 


\section{Figure 1}

A

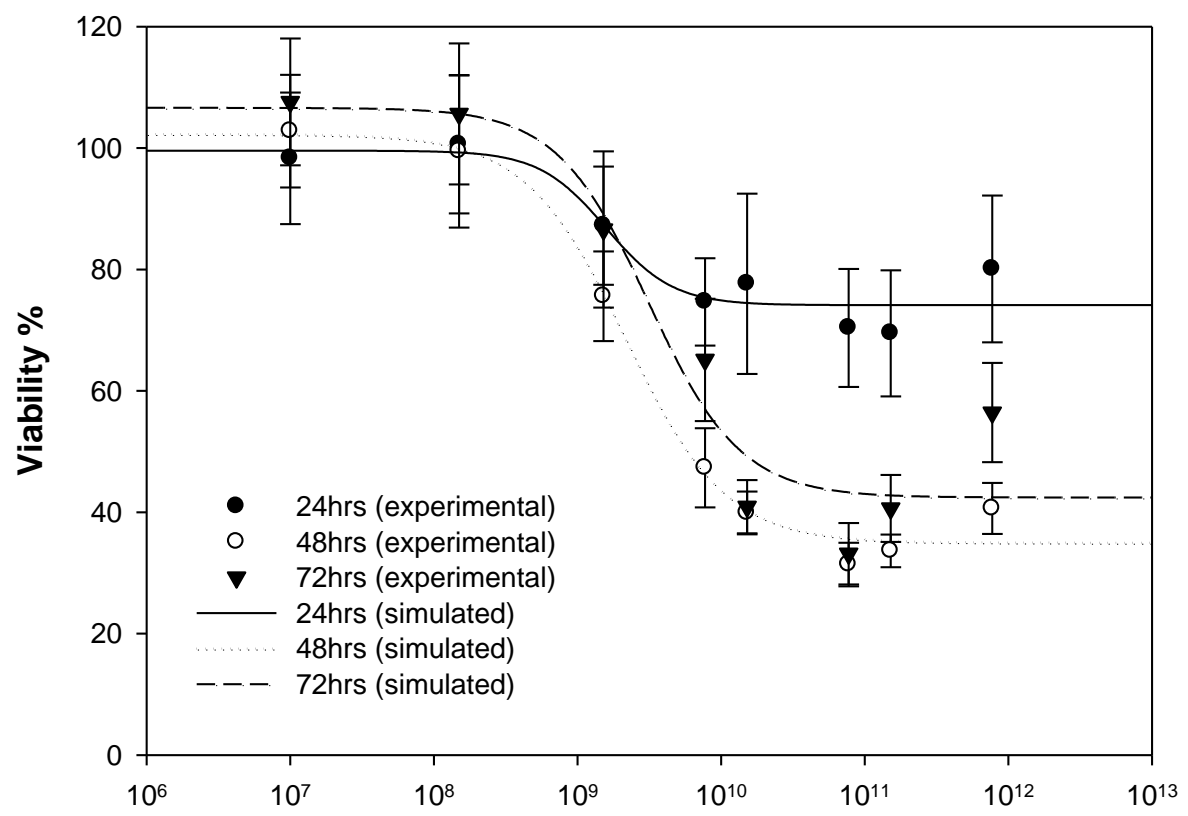

625

Particles/mL

B

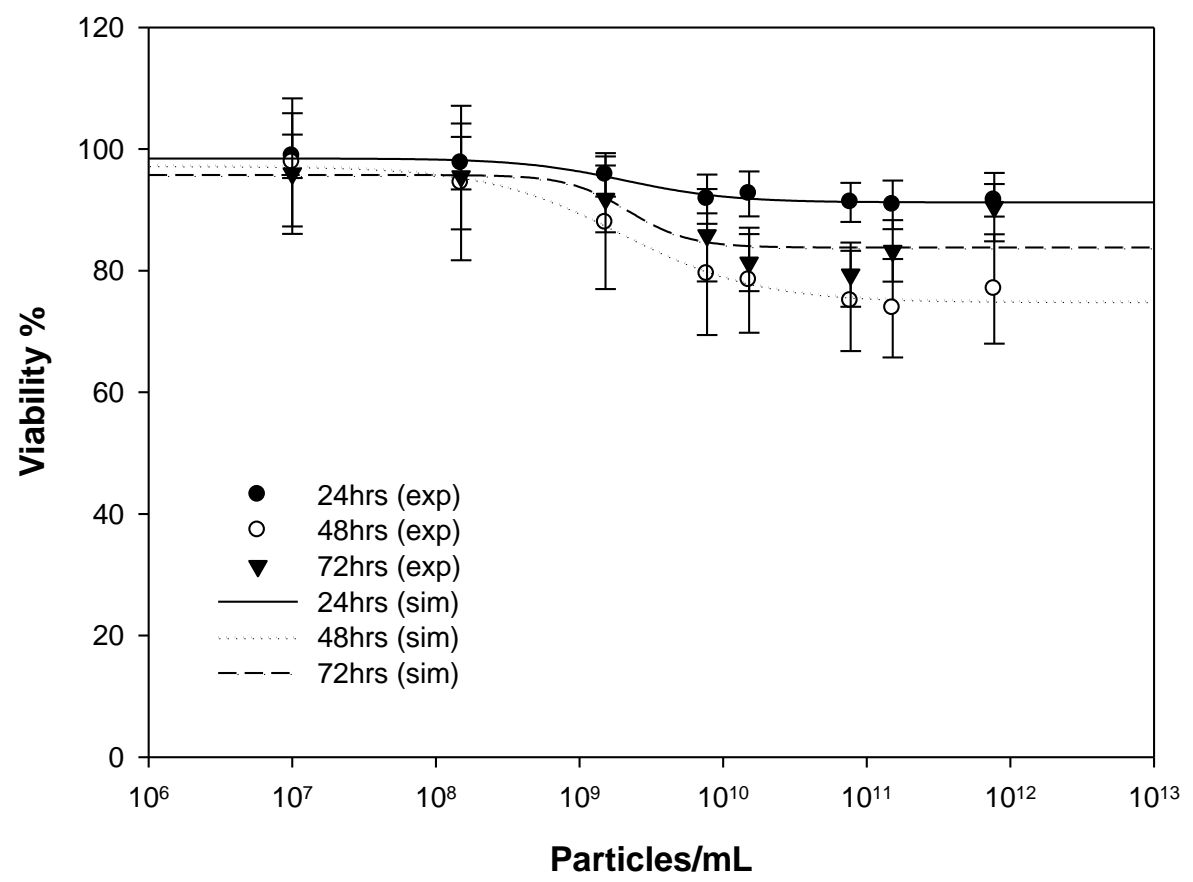


C

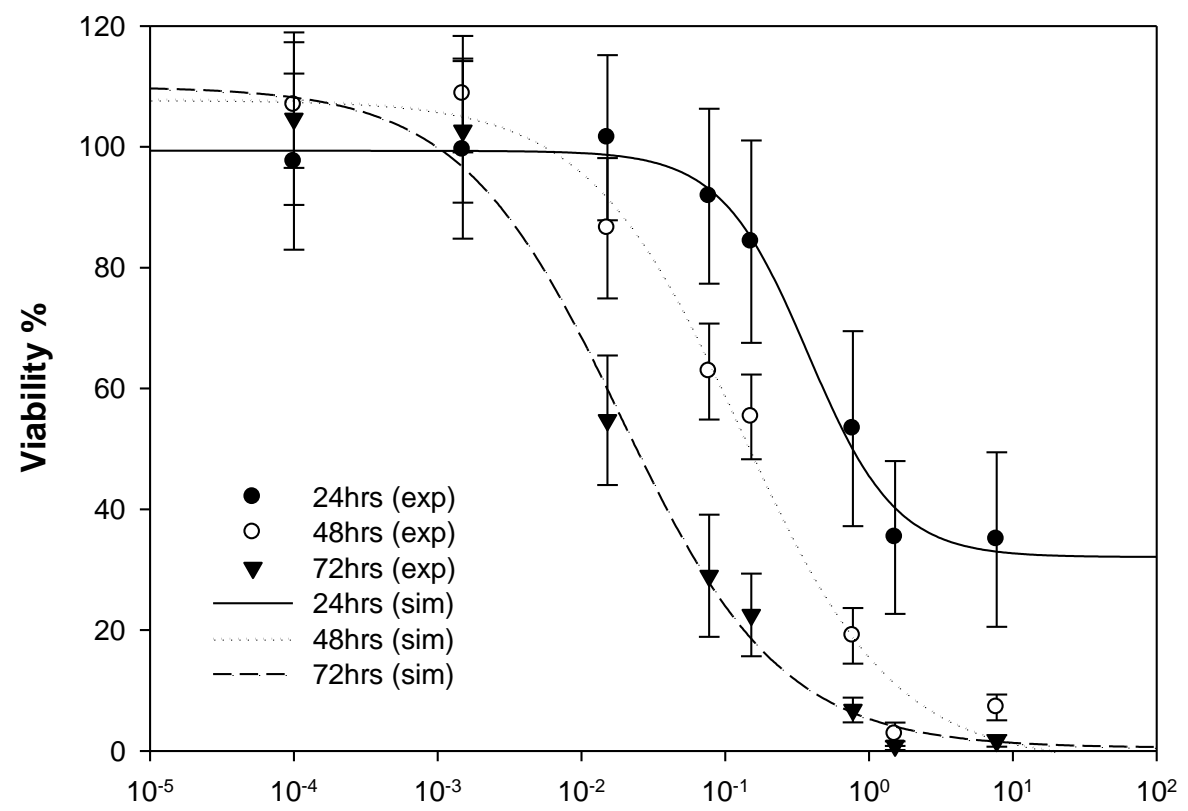

627

$\operatorname{DOX}(\mu \mathrm{M})$

D

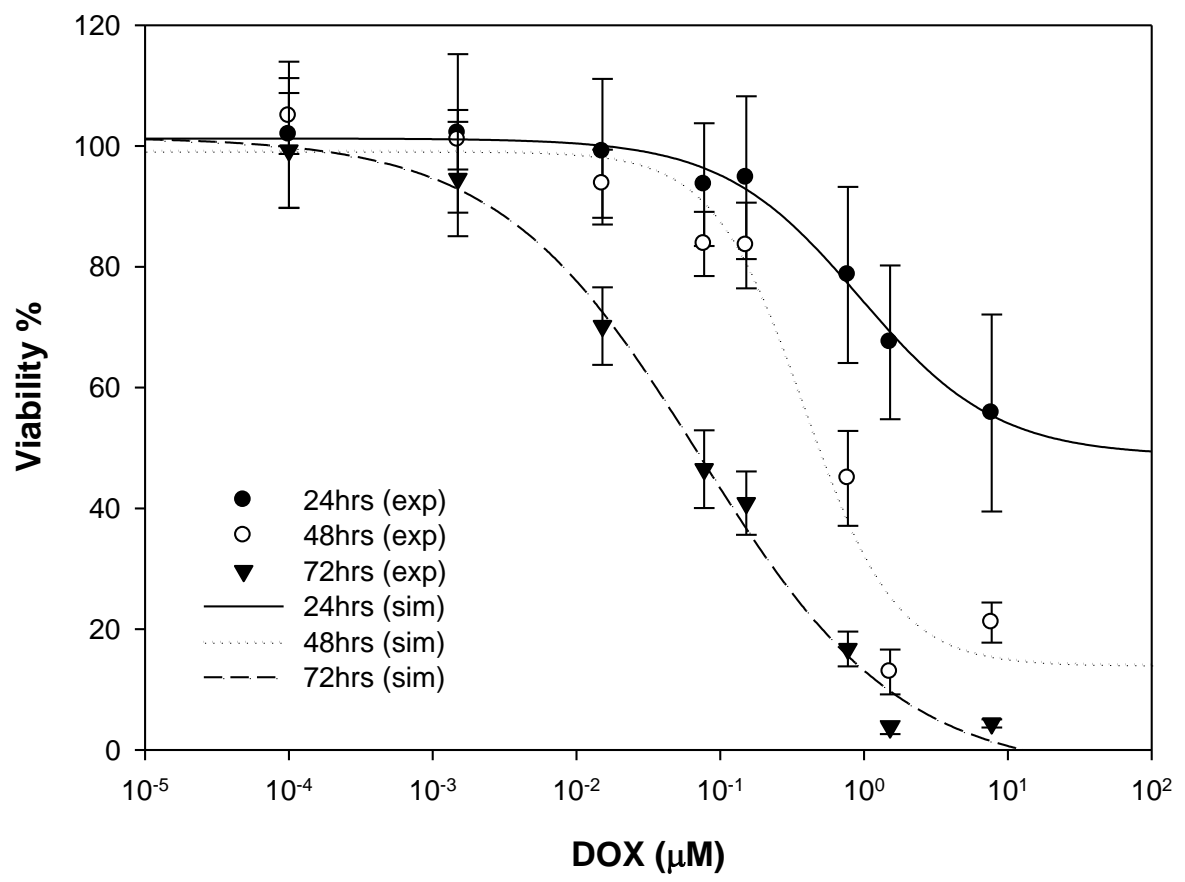


E

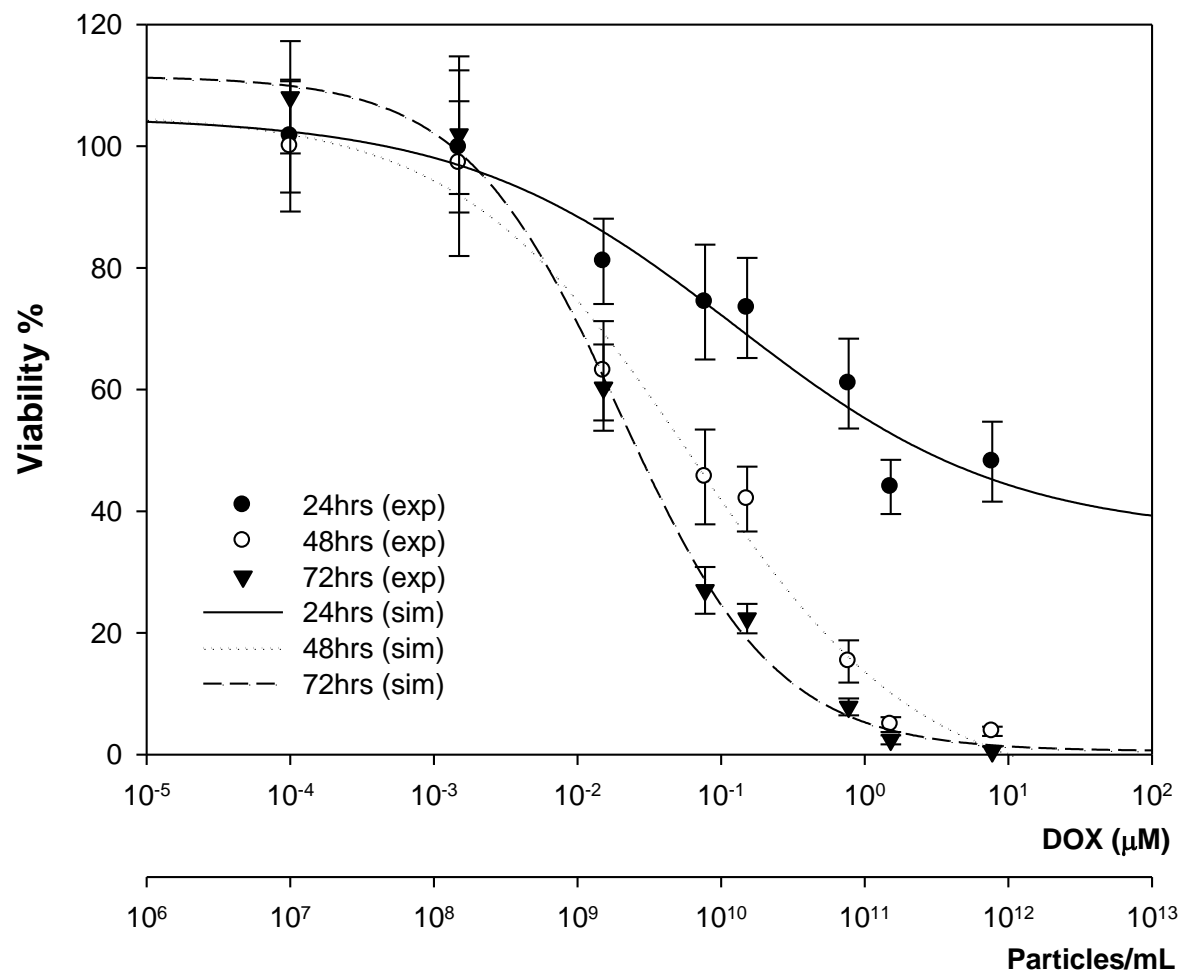

629

F

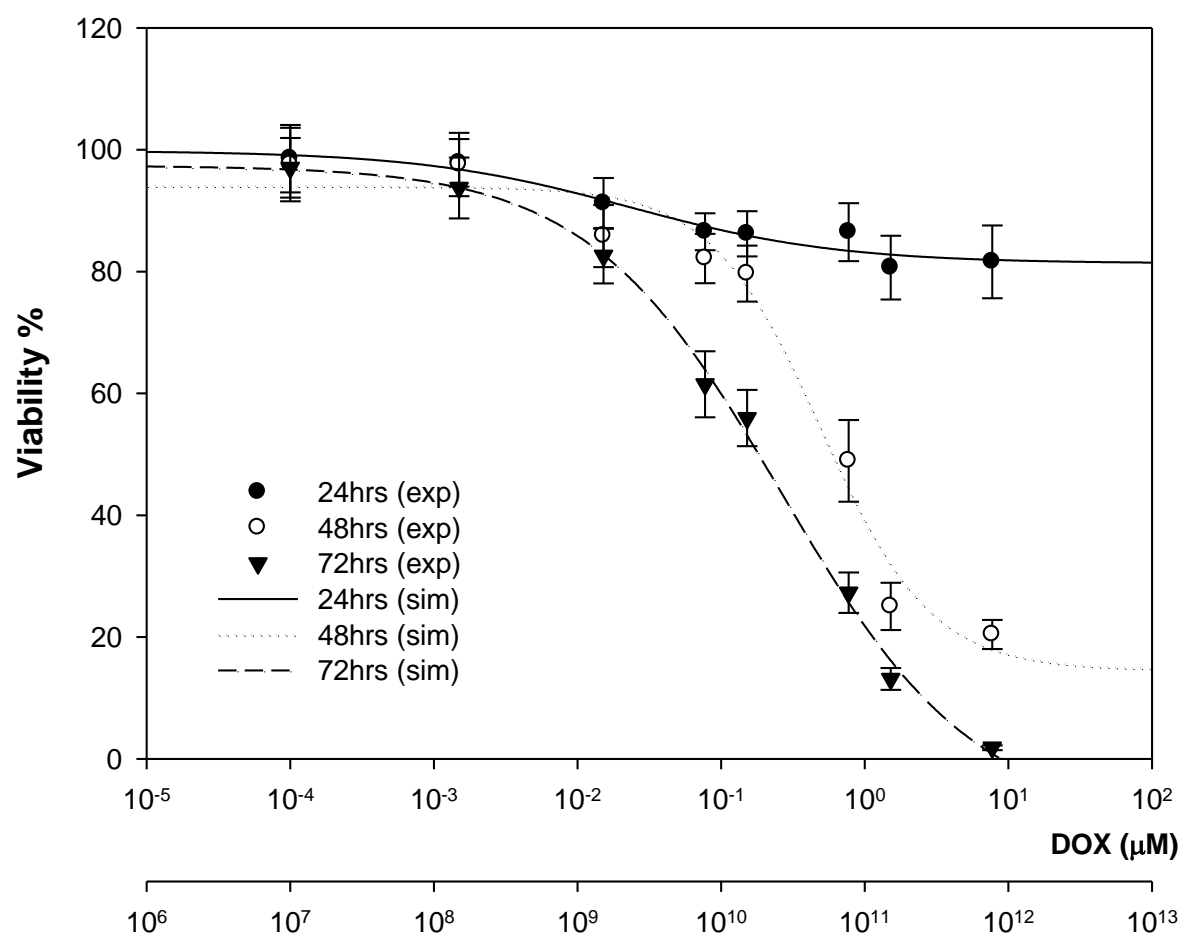

Particles/mL 
$631 \quad$ Figure 2

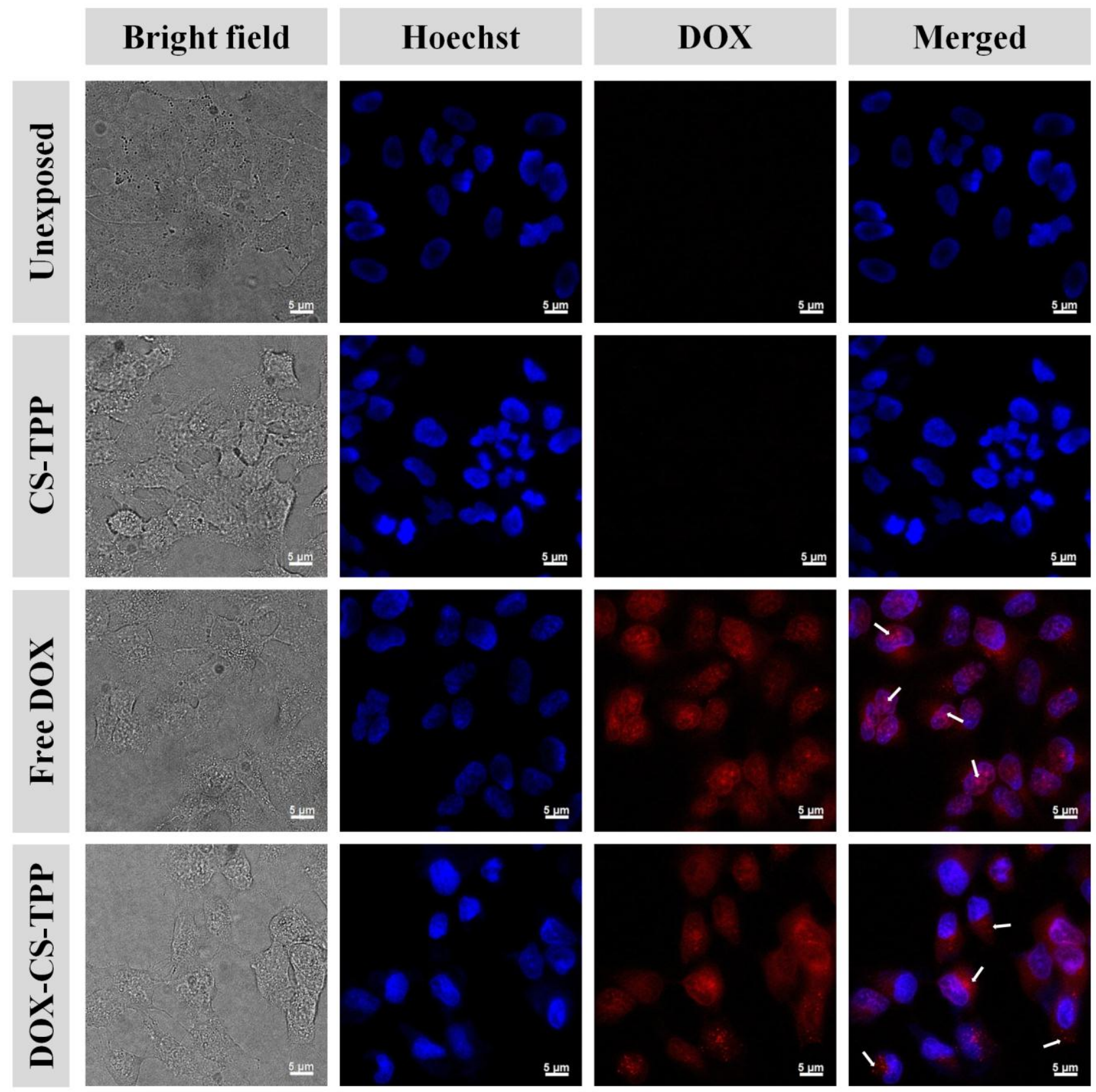

63 
634 Figure 3

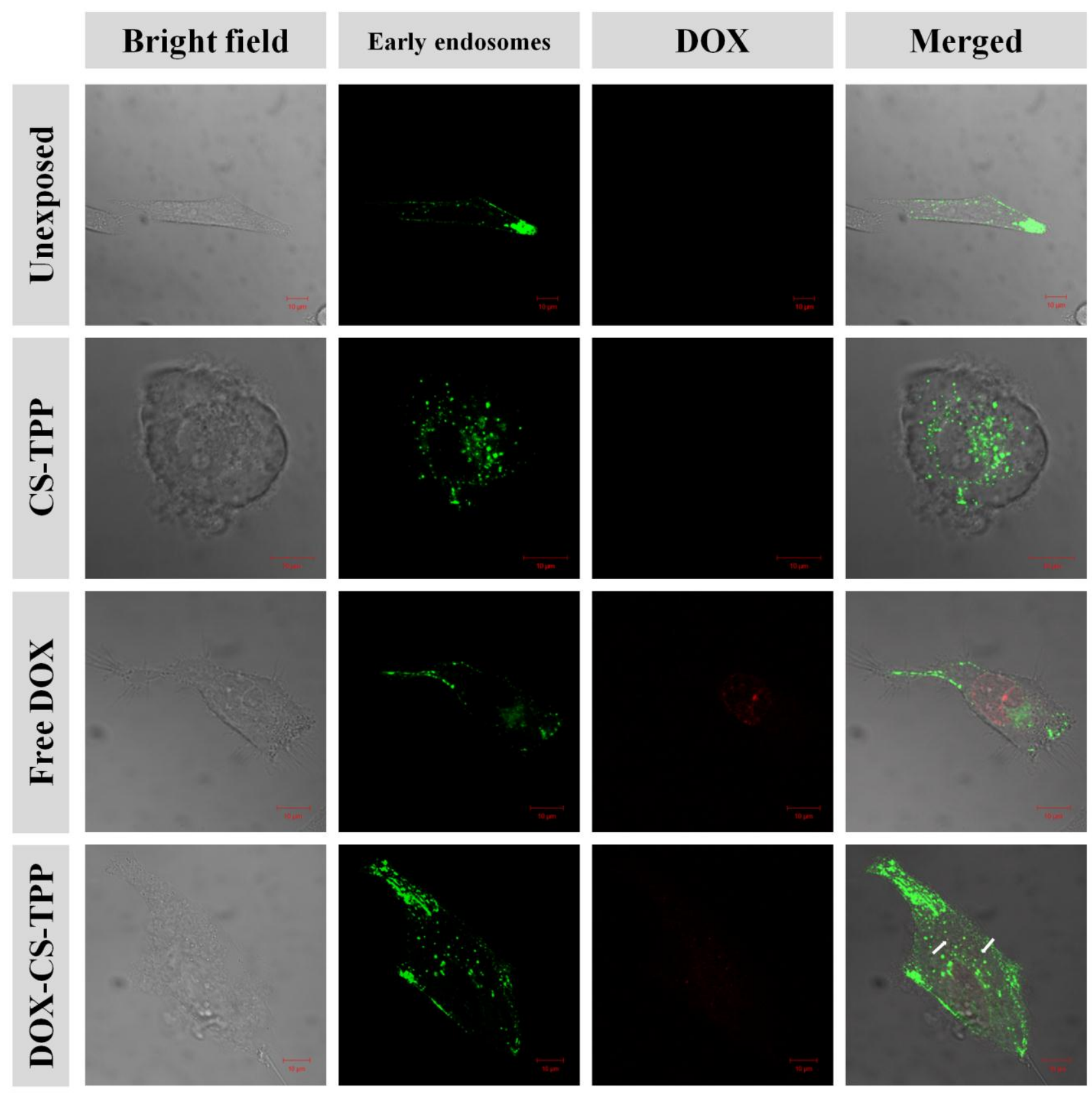

63 
$637 \quad$ Figure 4

A

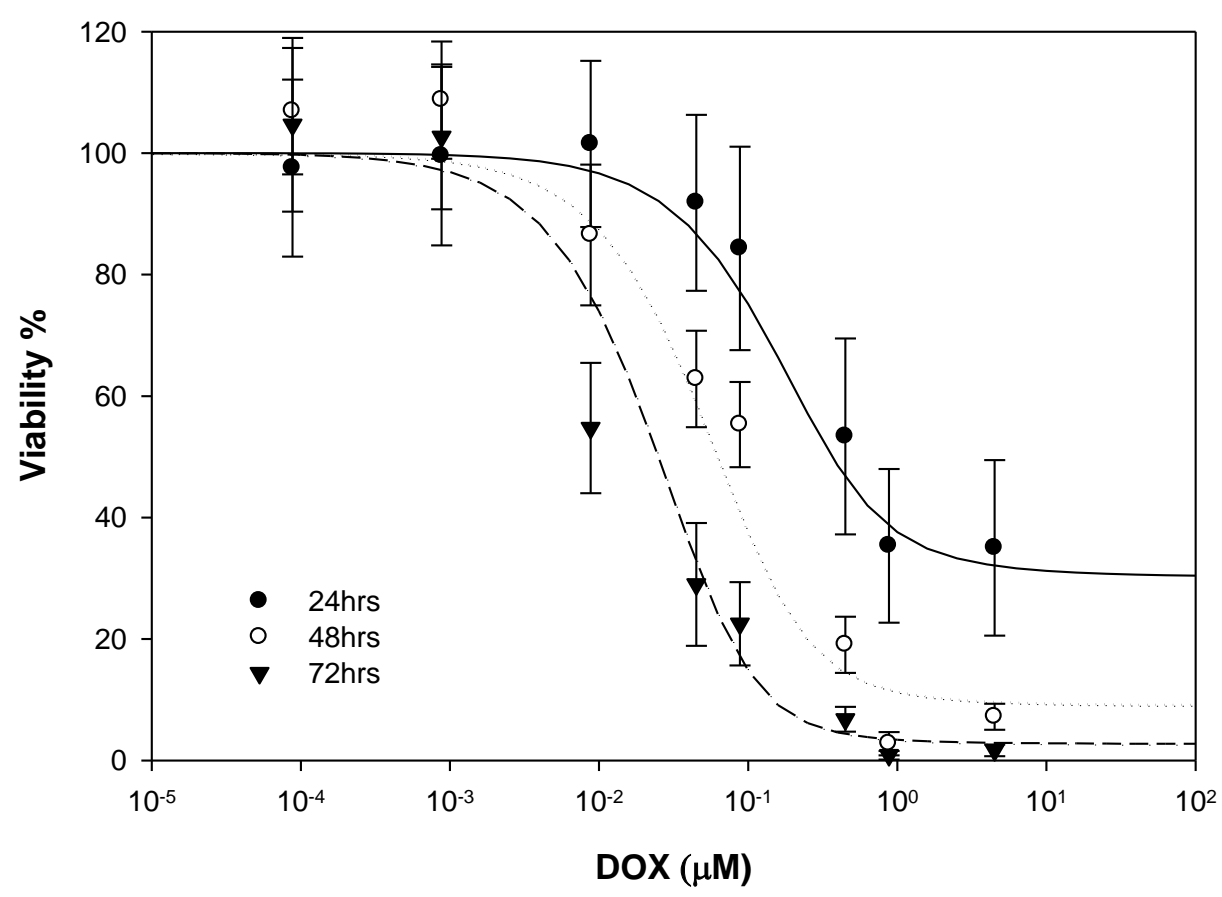

638

B

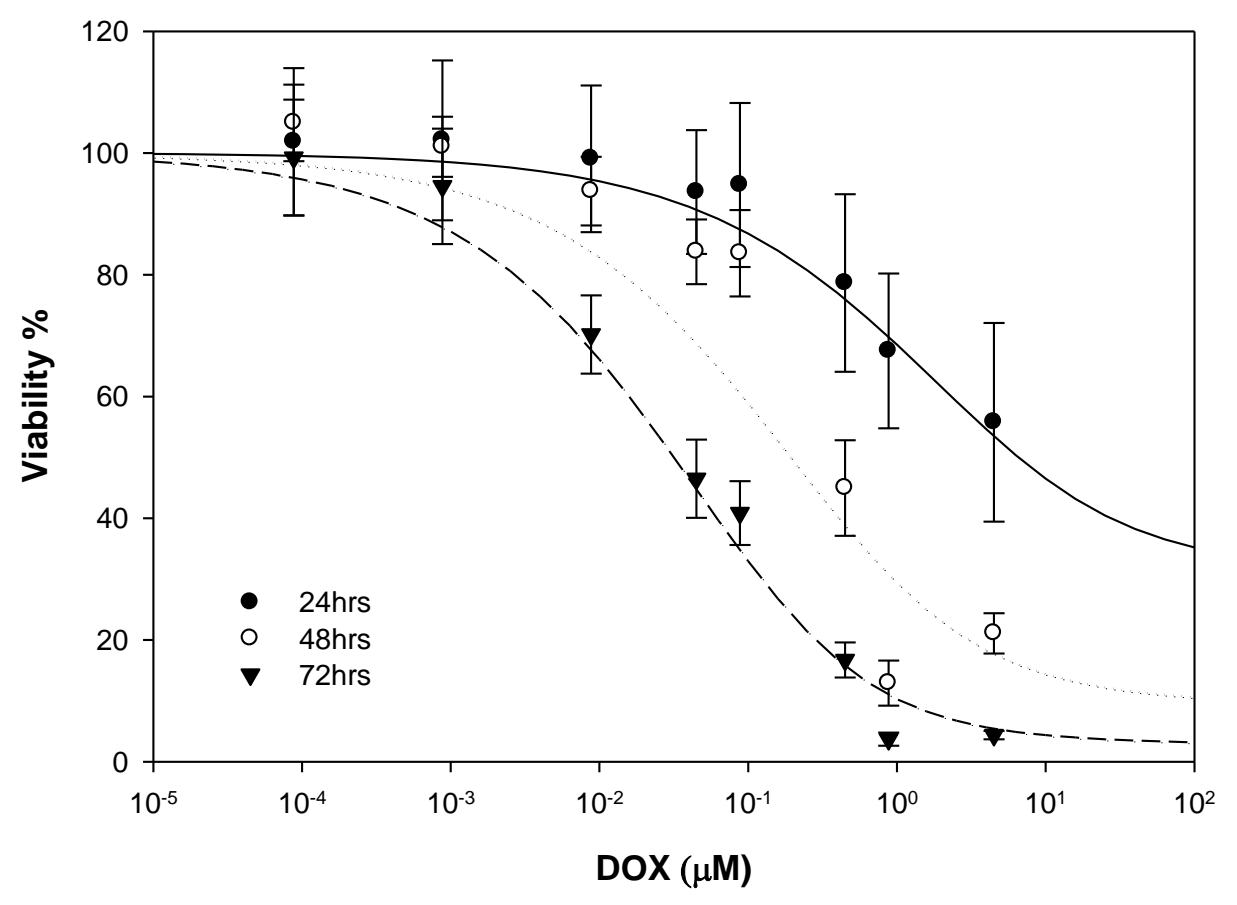

639 
C

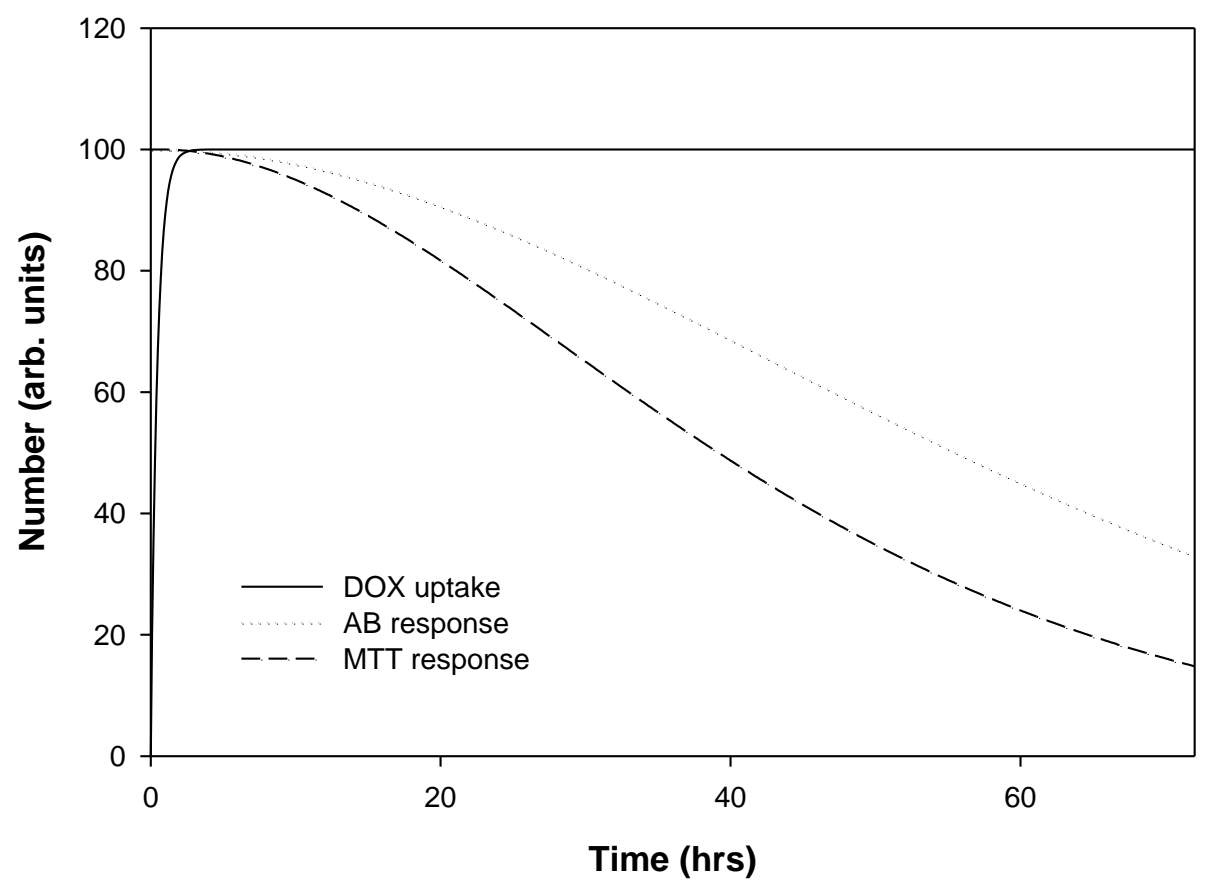

640

641

642

643

644

645

646

647

648

649

650

651

652

653

654

655

656

657

658 
659 Figure 5

A

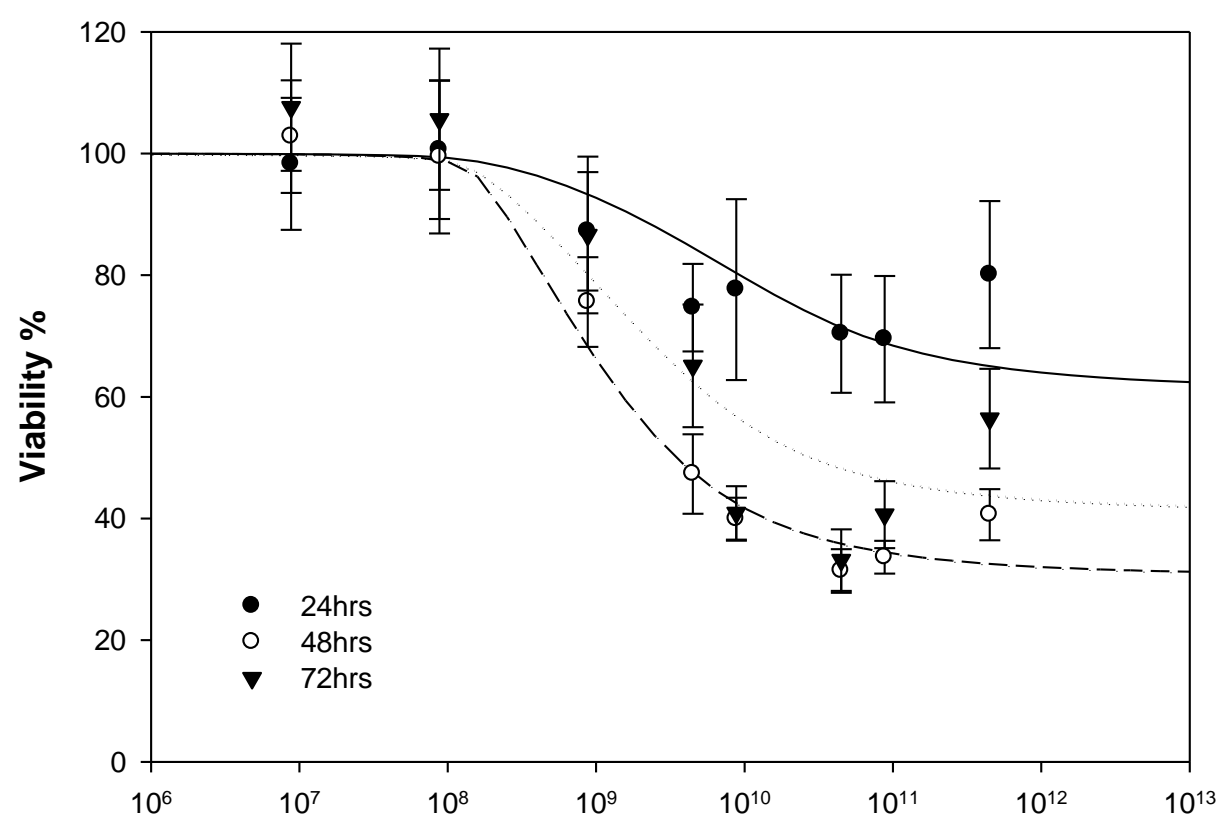

660

Particles $/ \mathrm{mL}$

B

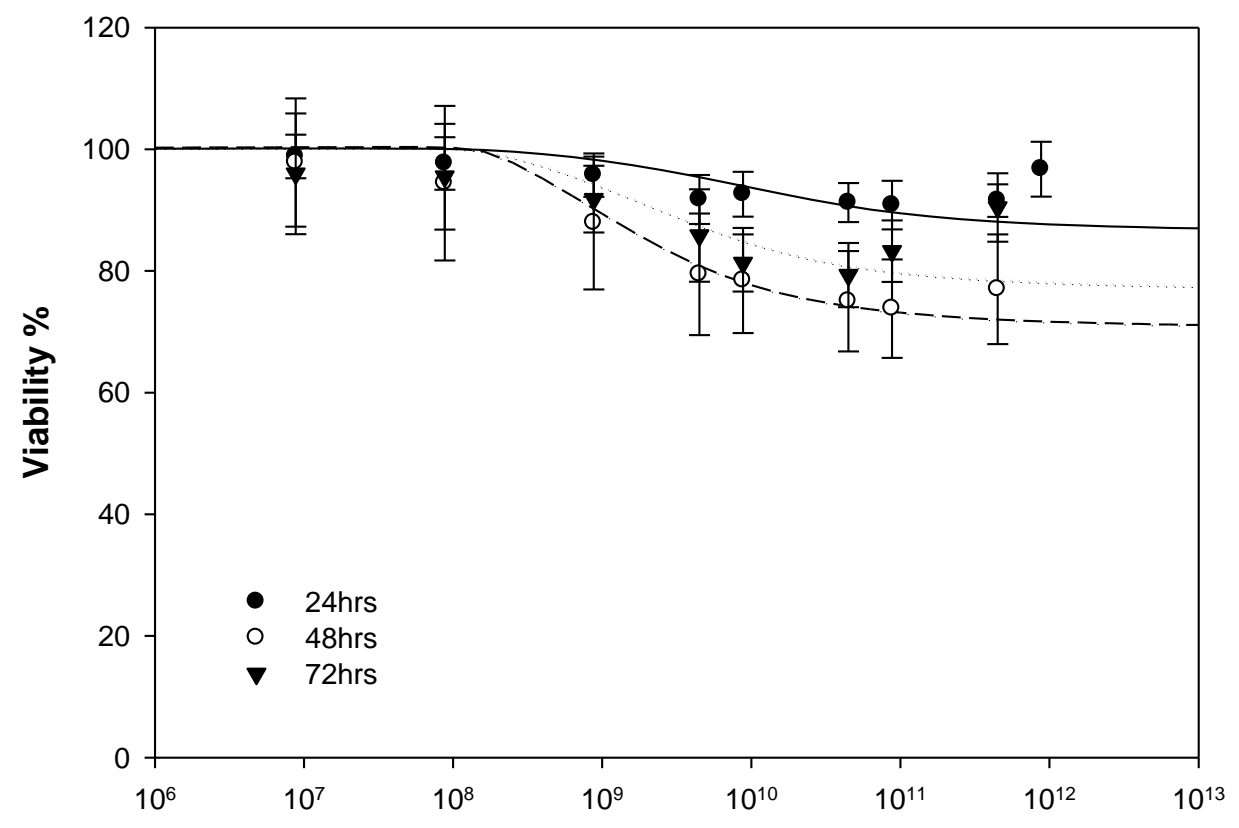

661

Particles/mL 
C

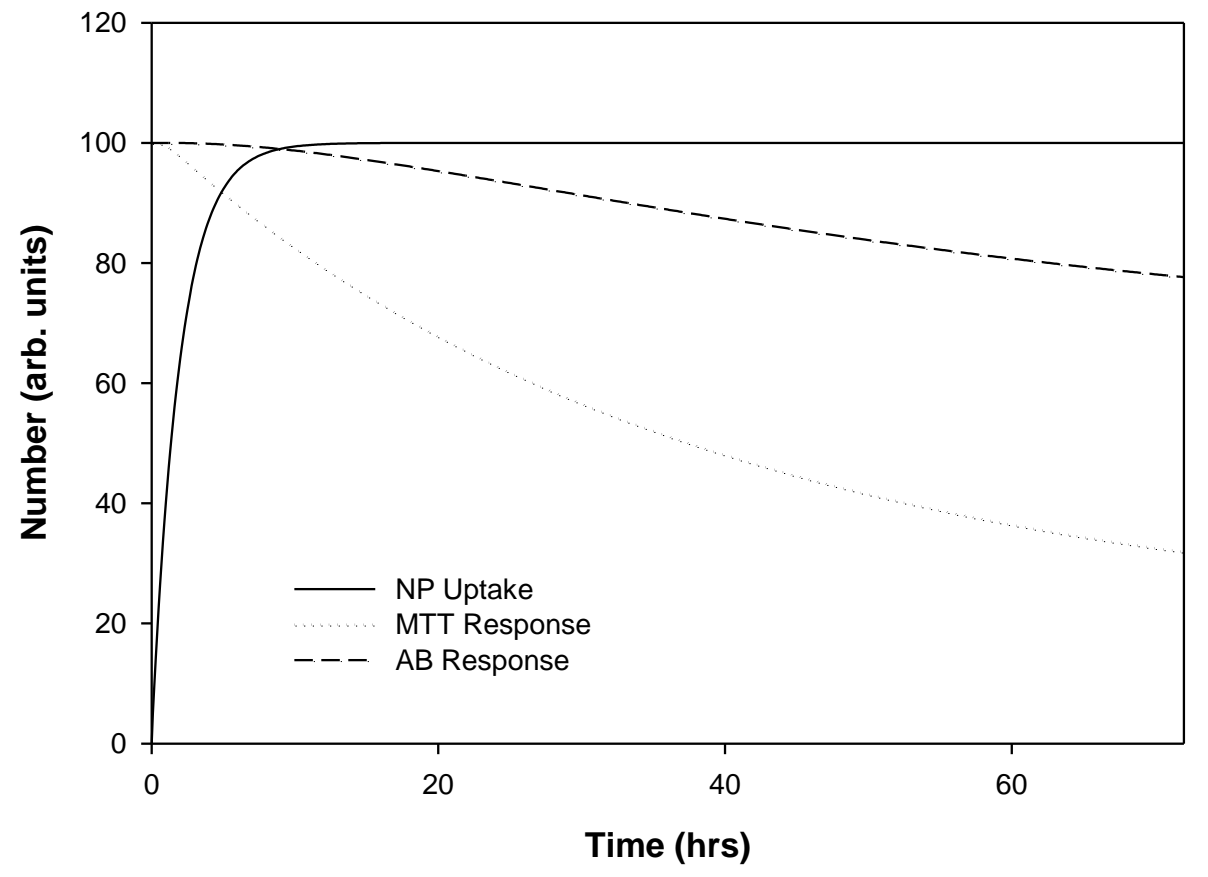

662

663

664

665

666

667

668

669

670

671

672

673

674

675

676

677

678

679

680 
Figure 6

A

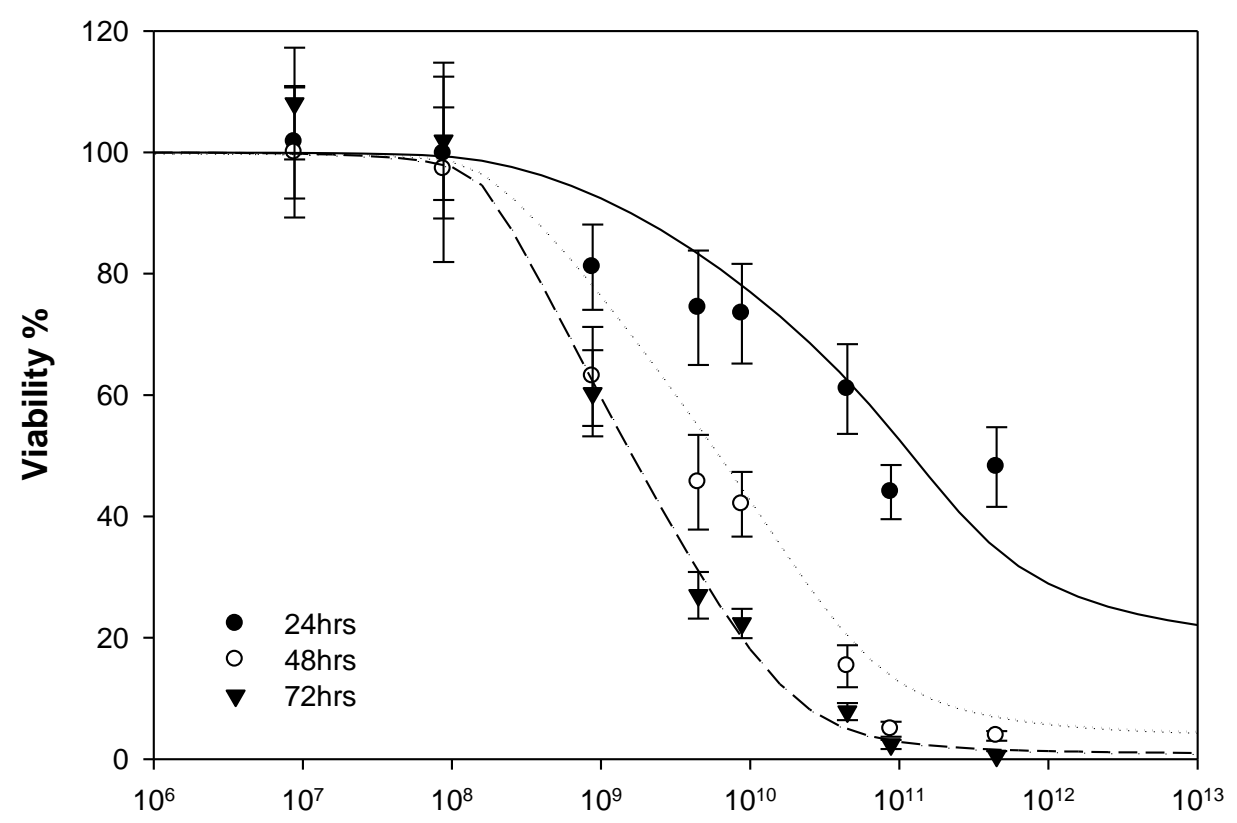

682

Particles/mL

B

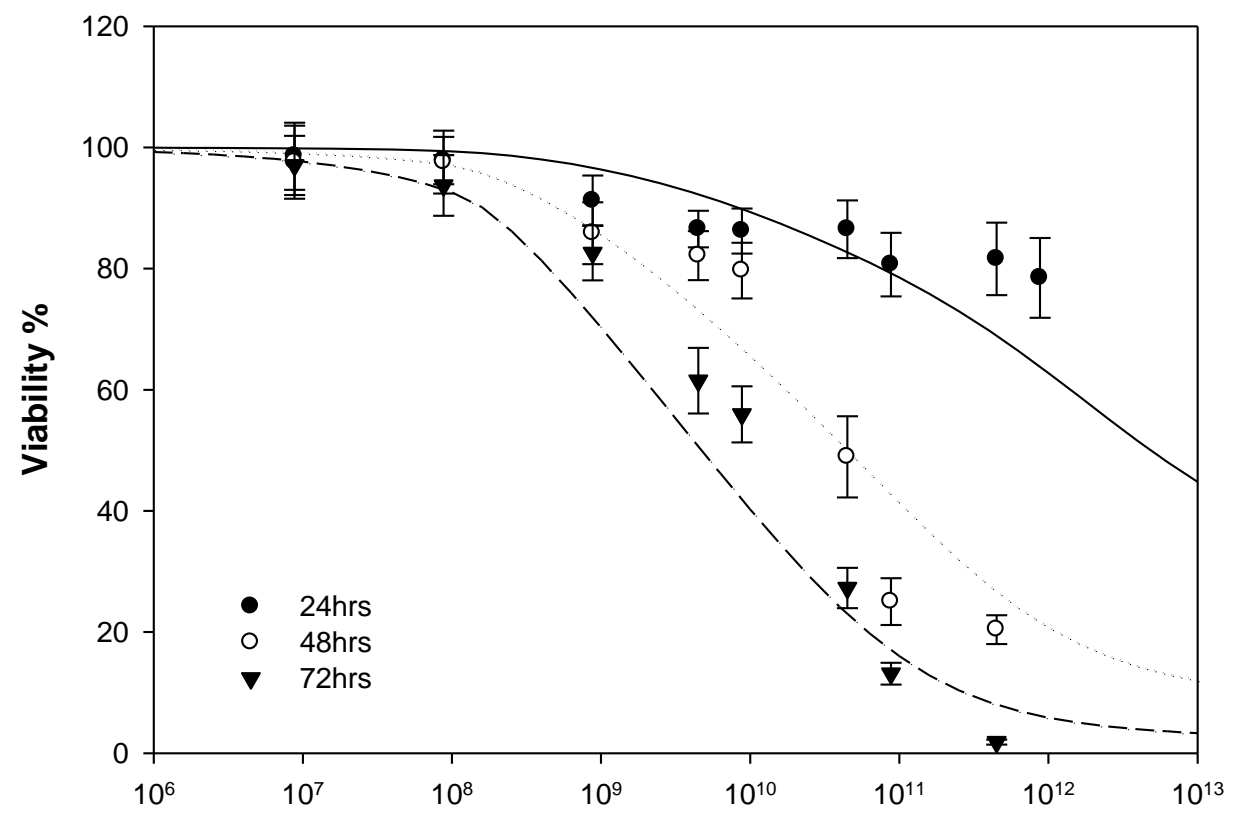

683

Particles/mL 
685

C

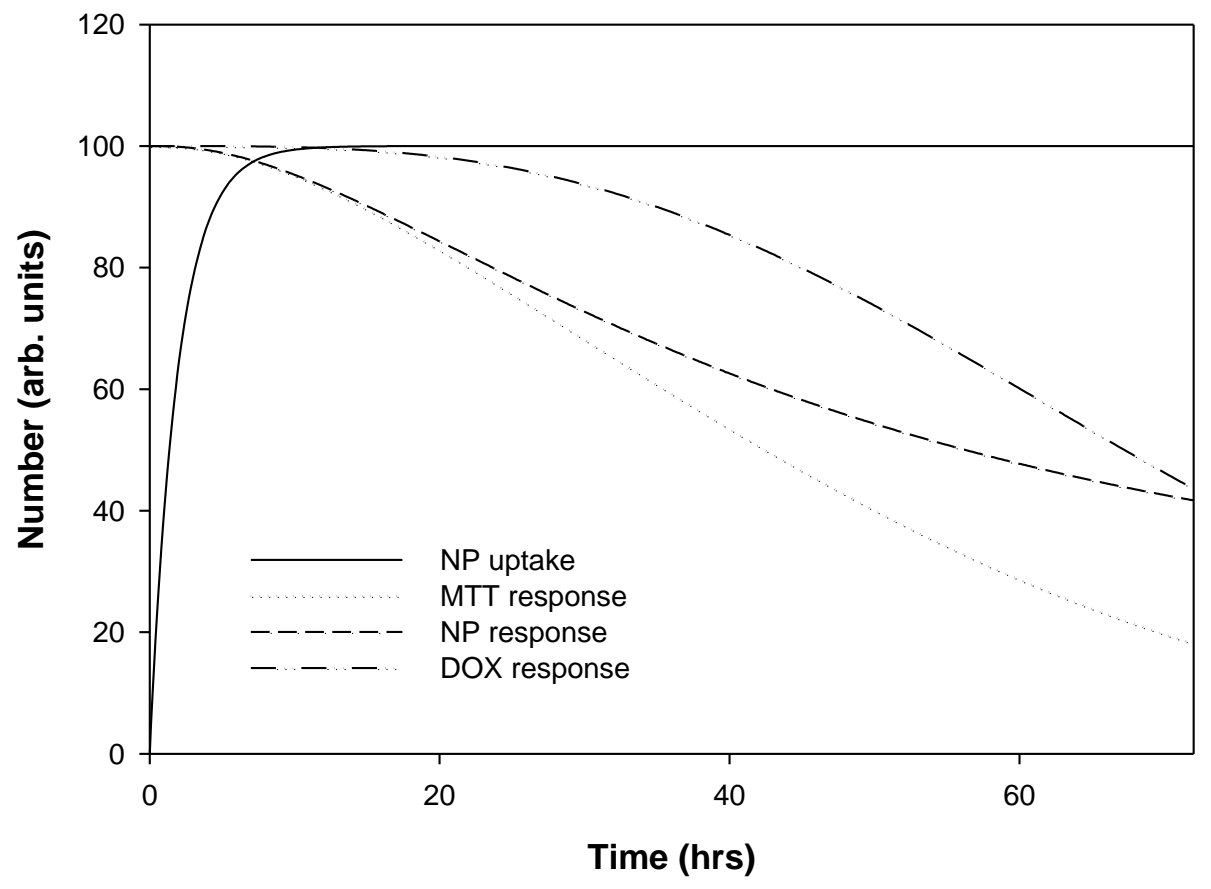

686

D

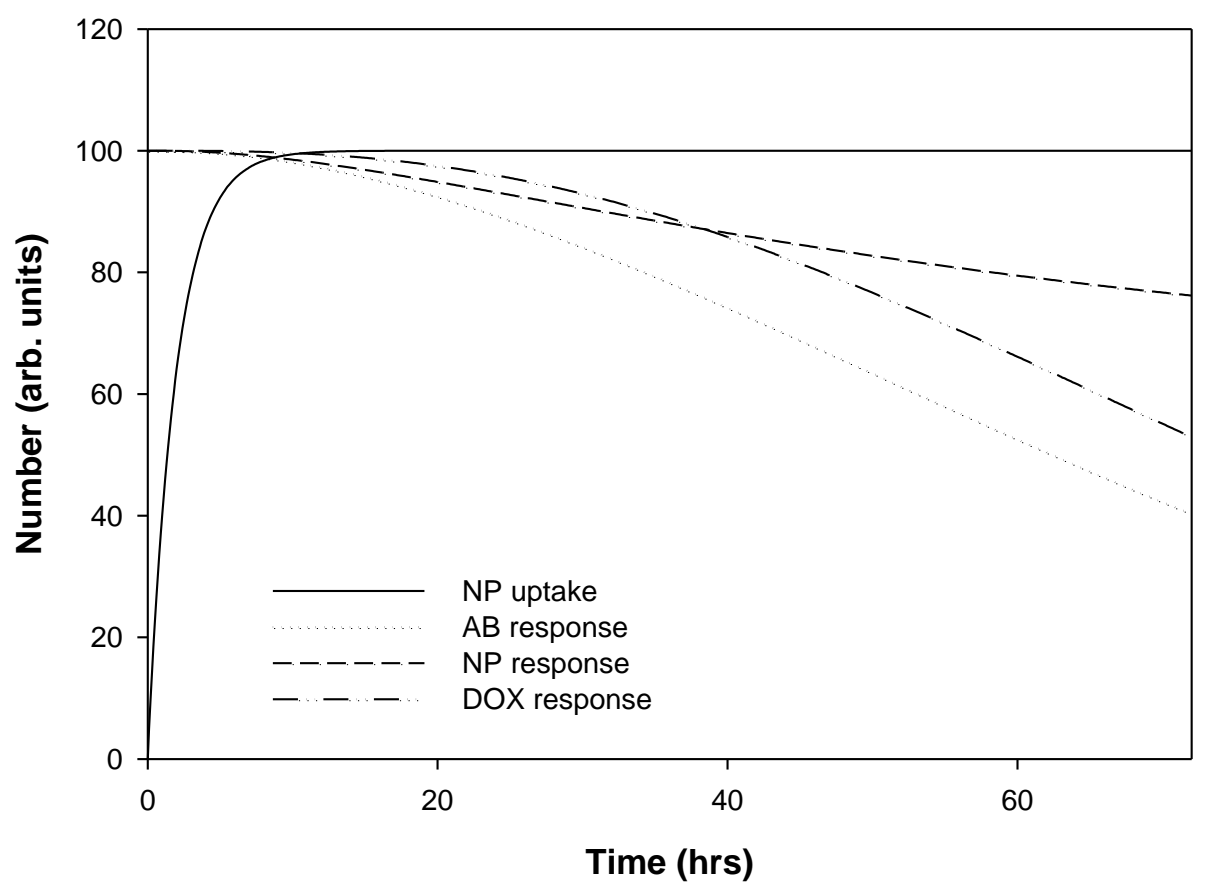

